\title{
Deskodetutako arrainak: atzo, gaur eta bihar
}

\author{
Oihane Diaz de Cerio* ${ }^{* 1,2}$, Eider Bilbao ${ }^{1}$ \\ ${ }^{1}$ CBET Research Group, Research Centre for Experimental Marine Biology \\ and Biotechnology (PIE-UPV/EHU), Euskal Herriko Unibertsitatea (UPV/EHU), \\ Plentzia, Euskal Herria. \\ ${ }^{2}$ University of Exeter, Biosciences, College of Life \& Environmental Sciences, \\ Exeter, UK. \\ oihane.diazdecerio@ehu.eus
}

DOI: $10.1387 /$ ekaia.13266

Onartua: 2015-03-31

Laburpena: Nahiz eta genomak eta transkriptomak sekuentziatzeko metodo berriak garatu diren, ingurune urtarreko organismo askoren sekuentzia ez dugu ezagutzen oraindik. Teleosteoen kasuan, kladoaren dibertsitate handia kontuan harturik, ezagutzen ditugun arrainen $\% 0$,2aren genoma besterik ez da sekuentziatu edo sekuentziatze asmotan dago. Artikulu honek beraz, helburu modura hartu du gaur egun teleosteoen sekuentzia genomikoei/transkriptomikoei buruz DNA-RNA datu-baseetan dagoena laburbiltzea, bai eta informazio honen jakintzak dakartzan onurak indartzea ere.

Hitz-gakoak: arrainak, sekuentziazioa, ingelesezko next generation sequencing (NGS), genoma, transkriptoma, ingelesezko digital gene expression (DGE).

Abstract: Although new genome and transcriptome sequencing techniques have been developed, sequence of most aquatic organisms is still unknown. In teleosts taking into account the high diversity of this clade, barely the $0.2 \%$ of teleost genomes has been sequenced or are at least planned to be sequenced. Thus, the aim of this article is to summarize the teleost genome/transcriptome sequence information available in DNA-RNA information reservoirs, as well as, to highlight the importance of using this knowledge.

Keywords: fish, sequencing, next generation sequencing (NGS), genome, transcriptome, digital gene expression (DGE).

\section{ARRAINEN GENE-KODEAREN EZAGUTZA: EGOERA ETA ERABILPENAK}

Arrainen taldeak 28.000 mila espezie inguru zituela estimatu zen 2006. urtean [1]; gaur egun ordea, 32.800 espezie aurki daitezke FishBase 
datu-basean, ugaztunek eta hegaztiek osatzen duten espezie kopuruaren bikoitza, alegia [1]. Aniztasun hori DNA/genoma mailan ere islatzen da, arrainek heterogenitate handia erakusten baitute DNA mailan, esaterako, DNA kantitatean [2], ploidia mailan, genomaren egituran [3], bai eta GCtan aberasturiko genomaren segmentuen antolaketa mailan ere [4]. Berriki, DNA eta RNA mailako ikerketak egiten hasi eta asko ugaritu dira arrainetan, besteak beste, eboluzioa, populazioen genetika, ekotoxikologia, akuikultura zein arrantza bezalako arloetan.

Garai batean, arrainen gene-kodea ezagutzeko erabiltzen ziren molekula mailako teknikak, Sanger sekuentziazio metodoaren [5] automatizazioan oinarriturik zeuden. Baina 2002. urtetik aurrera, Sanger metodoan oinarriturik ez zeuden beste teknika batzuk sortu ziren, ondorengo belaunaldiko sekuentziazioa (NGS) edo eta 2. sekuentziazio-belaunaldi gisa ezagutzen diren teknikak, hain zuzen ere. Teknika hauek DNA paraleloki eta masiboki sekuentziatzea ahalbidetu zuten, pirosekuentziazioa eta ingelesezko «Massively parallel signature sequencing» izeneko (MPSS; Lynx Therapeutics, Hayward, USA) metodoak erabiliz. Pirosekuentziazioak DNAren ekoizpenean sortzen diren pirofosfatoak neurtzen ditu, eta 1988. urtean garatutako teknika izan arren [6], ez zen ospetsu egin 2002. urtean MPSS teknikarekin uztartu zen arte [7]. Konbinazio honi esker, Sanger metodoarekin, 1200 base pareko sekuentziak lortzetik, luzera ezberdinetako milaka edota milioika sekuentzia lortzera iritsi ginen. Hala ere, metodoa ez zen 2005. urtera arte merkaturatu, 454 Life Sciences izenekoaren eskutik (http://www.454.com, Roche Applied Science, Penzberg, Germany). Teknologia 3 pausu nagusitan gauzatzen da: DNA-liburutegiaren prestakuntza, sekuentziazio irudiak atzematea, eta datuen analisia. Ondoren, hiru pauso hauen teknika-konbinazioek beste metodo batzuei ateak irekiko zizkien, besteak beste, Illumina, Roche, eta Nanopore [8].

Beraz, NGS metodoek Sanger metodoa alboratu egin zuten, eta azkeneko hamarkadan edozein organismoren sekuentziaren datuak lortzeko gaitasuna esponentzialki erraztu zuten [9]. Horrela, 2012ko uztailean nukleotido-sekuentzien datu-basean arrain hezurdunen bilaketa «Teleostei» terminoaren arabera burutuz gero, 772.583 mRNA sekuentzia topa zitezkeen, horietatik 70.591 erreferentzia-sekuentziak ziren (ref-seq). «Expression sequencing tag» (EST) sekuentziei erreparatuz gero ordea, 5.245.708 sarrera zeuden, 5 espezie nagusitan banatuta: zebra arraina (Danio rerio), medaka arrunta (Oryzias latipes), izokina (Salmo salar), katuarraina (Ictalurus punctatus) eta amuarraina (Onchorynchus mykiss). 2 urte geroago ordea, bilaketa beraren emaitza ia hamar aldiz handiagoa da; hau da, guztira 7.121.967 mRNA, 493.972 erreferentzia-sekuentzia eta 5.604.421 EST sarrera daude. Azken hauetan, ez da aldaketa nabarmenik egon aipaturiko bost espezie sekuentziatuenetan, eta beraz, 360 mila sekuentzien sarreraren emendioa arrain espezie berrietan gertatu da. 
Deskodetutako arrainak: atzo, gaur eta bihar

Bi urteotan gertatutakoak ondo laburtu eta islatzen ditu azken hamarkadan genomika eta transkriptomikaren arloan gertatutakoak. Sekuentziaziorako teknika berriek nukleotidoen informazio iraultza ekarri dute, horrela, informatikaz eta ingeniaritzaz lagunduta, orduetako edo egunetako denbora tartean, gene-kode andana lor daiteke, eta horrek era berean, ahalbidetu du ezagunak ez diren espezieen informazioan sakontzea. Gainera, «Feedback» positiboaren ondorioz, zenbat eta informazio gehiago ezagutu, orduan eta homologia bidezko bilaketa eta diseinu egokiak gauzatzeko aukera handiagoak sortzen dira eta ezezagunak diren espezieetan kidetasun bidezko ikerketak ahalbidetzen dira.

Lan honek helburu modura du gaur egun, datu-baseetan aurki ditzakegun arrainen sekuentzien gaineko molekula mailako informazioa laburbiltzea, sekuentziatuta dauden genoma/transkriptometatik sekuentziatzear daudenetara joanda.

\section{ARRAINEN GENOMA DATU-BASEETAN}

Genomen GOLD datu-baseak (www.genomesonline.org) 2014ko maiatzean azaldu zuen, bukatutako 9.191 eukariota-genomaren egitasmoetatik, 933 kordatuei zegozkiela. Bertan, $\approx 60$ bukatuta edo bukatzear zeuden arrainen genomaren sekuentziazio-egitasmoak ziren (NCBI datu-basean «actinopterygii» gisa bilaketa eginez, 56 emaitza). Datuok, gnaostomatuen klaseak, zehazki aktinopterigio kladoak, duen dibertsitate handiarekin alderatuta arrainen inguruan dagoen informazio-urritasuna begibistan geratzen da.

Filogenian atzera eginez, berezitasun primitiboak dituzten ornodunetan, Agnato taldean, itsasoko lanproiaren (Petromyzon marinus) genomaren lehenengo antolaketa 2013an bukatu zen [10]. Urte berean iragarri ziren GOLDen, bai , Lanproi japoniarraren (Lethenteron japonicum) genomaren lehen antolaketa [11], bai eta Artikoko lanproiaren (Lethenteron camtschaticum), genoma-proiektua (PRJNA192554). Filogenian aurreratuago dagoen kondriktie Australiako marrazo mamua (Callorhinchus milii) ere sekuentziatu dute dagoeneko [12]. North East Cyberinfrastructure Consortium izenekoek «Kanadako arraia» arrainaren (Leucoraja erinacearen) genomaren lehenengo antolaketak aurkeztu $[13,14]$ eta mielga pikart (Squalus acantias) espeziearen genoma-proiekturako ildoak plazaratu dituzte.

Horrela, kondriktioen inguruko genoma-proiektuak eta sekuentziatutako genoma guztiak batuta, duela gutxi argitaratu dute SkateBase deritzon datu-basea (http://skatebase.org) [15], orain arte lortutako kondriktie genoma datuak biltzen dituena.

Teleosteoei dagokienez, sekuentziaturiko lehenengo genoma, 2002an plazaratu zen eta Takifugu rubripres arrainarena da [16]. Bi urte geroago, 
ur gezetako Tetraodon nigroviridis arrainarena plazaratu zen [17]. Bi arrain espezie hauek dute ornodunen artean ezagutzen den genomarik txikiena, gizakiarena baino 7 aldiz txikiagoa.

Beraz, T. rubripres eta $T$. nigroviridis eredu ezin hobeak bilakatu dira, ornodunen genomaren eboluzioa, eta ondorioz organismoen eboluzioa ulertzeko. Gaur egun ere, kondriktiekin batera, eboluzioa aztertzeko erabili ohi dira [13-17]. Biek ornodunen genoman horren arruntak diren DNA errepikak, edo orokorrean deituriko DNA zaborra falta dute. Ezaugarri honek, gene sekuentzien analisia zein geneen gune erregulatzaileen bilaketa errazten ditu. 10 urte ondoren, tetraodonen genoma plazaratu zuen institutu berak, Genome Institute izenekoak, ezagutzera eman du amuarrainaren (Onchorrynchus mykiss) genoma (1. taula); lan horretan, gainera, salmonidoen eboluzioaren esparruan ekarpena egiten dute, eta diploidia prozesuaren oinarriak ikertzen ari dira [18].

2014ko abenduan, Ensembl genomen datu-basean (http://www . ensembl.org/index.html) plazaratua duten beste teleosteo batzuk hurrengo hauek dira: medaka (Oryzias latipes) [28-29], bakailaoa (Gadus morhua) [30], kolekantoa (Latimeria chalumnae) [31], hegoaldeko «platifish» arraina (Xiphophorus maculatus) [32-33], espinosoa (Gasterosteus aculeatus) [24], Niloko tilapia (Oreochromis niloticus) [26], Mexikoko tetra arraina (Astyanax mexicanus) [34], musker arraina (Lepisosteus oculatus) [35], Amazoniako molia (Poecilia formosa), eta zebrarraina (Danio rerio) (1. taula). Hauez gain, 2014ko urrian, NCBIko «Genome» datu-basean bilaketa eginez gero, urte batetik besterako genoma berriak eta antolaketa egoera ezberdinetan argitaratutako genomak ezberdindu daitezke . Guztira, 45 sarrera-espezie aurki daitezke , 39 espeziek osatua; hauetako batzuk behin baino gehiagotan sekuentziatu dira, adibidez, D. rerio (1. taula). Amaitzeko bidean dauden beste hainbeste proiektu ere badaude, besteak beste, katuarrainaren (Ictalurus punctatus) geneen antolaketa eta mapaketa, Auburn University eta USDA-ARS Catfish Genetic Research Unit izenekoaren eskutik (http://www.catfishgenome.org/cbarbel/) [36]. Hauek, katuarrainaren genoma eta beste 4 arrain ereduren genomak konparatu zituzten, eta ondorioztatu zuten katuarrainaren genoma eta zebrarrainarena direla antzekoenak [36].

Azkenik, gogoratu beharra dago Beijing Genomics Instituteko 10K landare eta animalien genoma sekuentziatzeko proiektuari esker (BGI; http:// www.genomics.cn), arrain espezie berrien genoma hemendik gutxira irakur daitekeela . Proiektu honek xede modura hartu du ekonomikoak eta zientzia munduan interesgarriak diren espeziak sekuentziatzea, hau dela eta, eredu ez diren arrain espezie ugari proposatu dira [37]. Horrela, Bernardi eta kolaboratzaileek, 2012 BGI-10K proiektuan sekuentziatzen ari diren eta dagoeneko sekuentziatuta dauden arrainen genomak laburbilduta 100 arrain espezieren genomaren sekuentziazio posiblea argitaratu zuten [36]. 


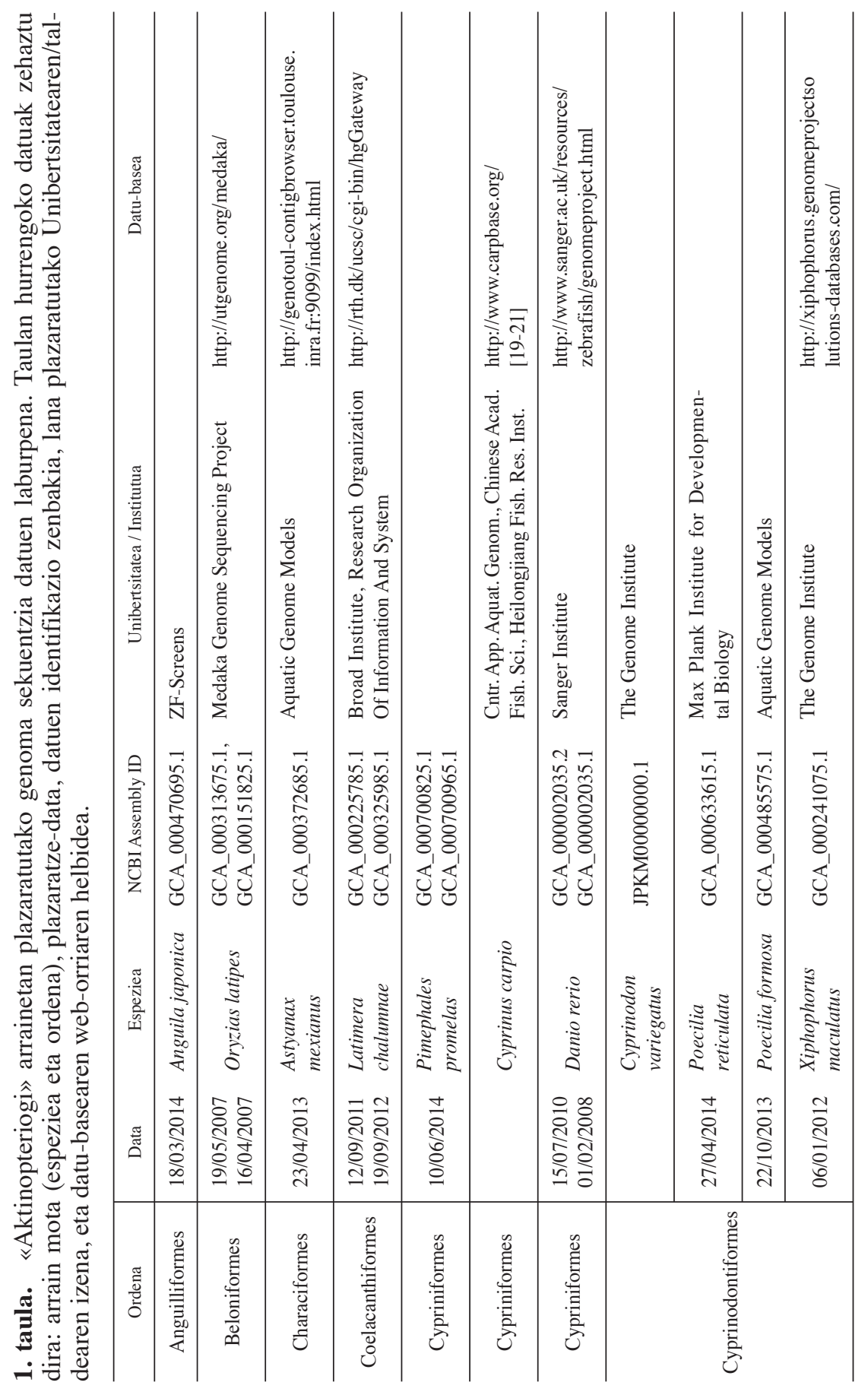

EKAIA, 28 (2015) 


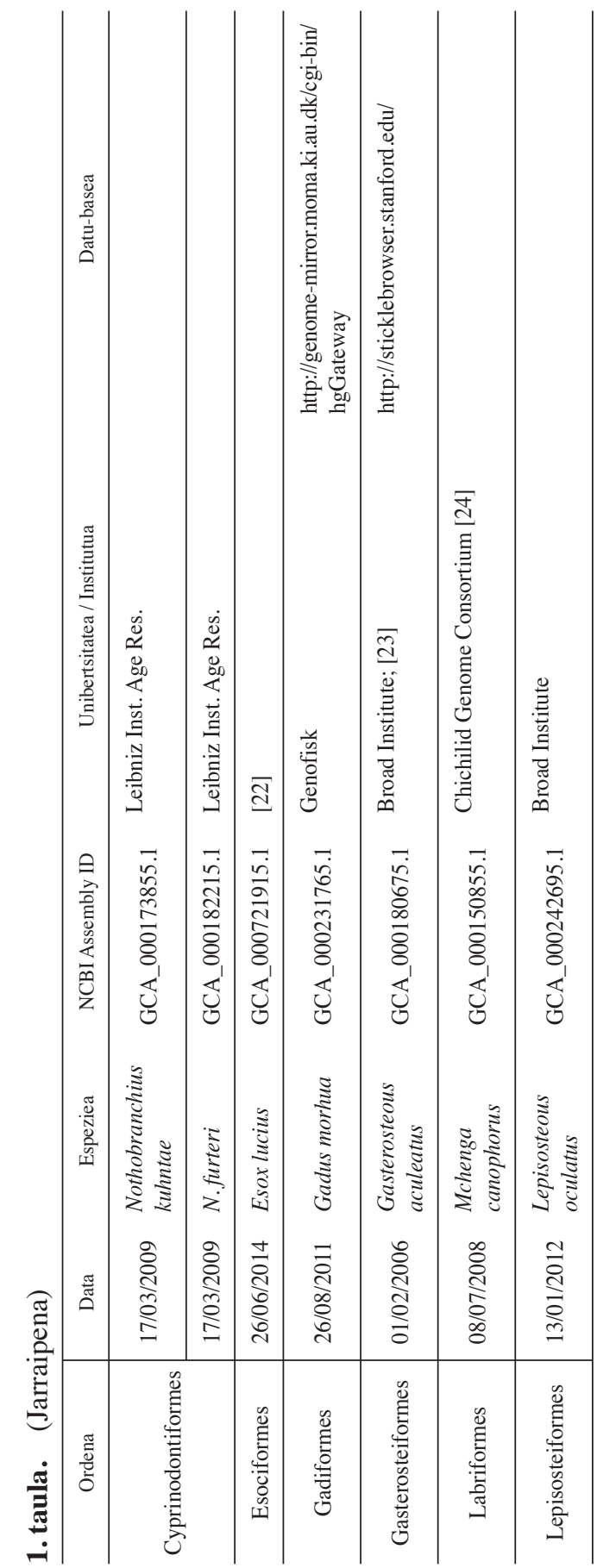

156

EKAIA, 28 (2015) 


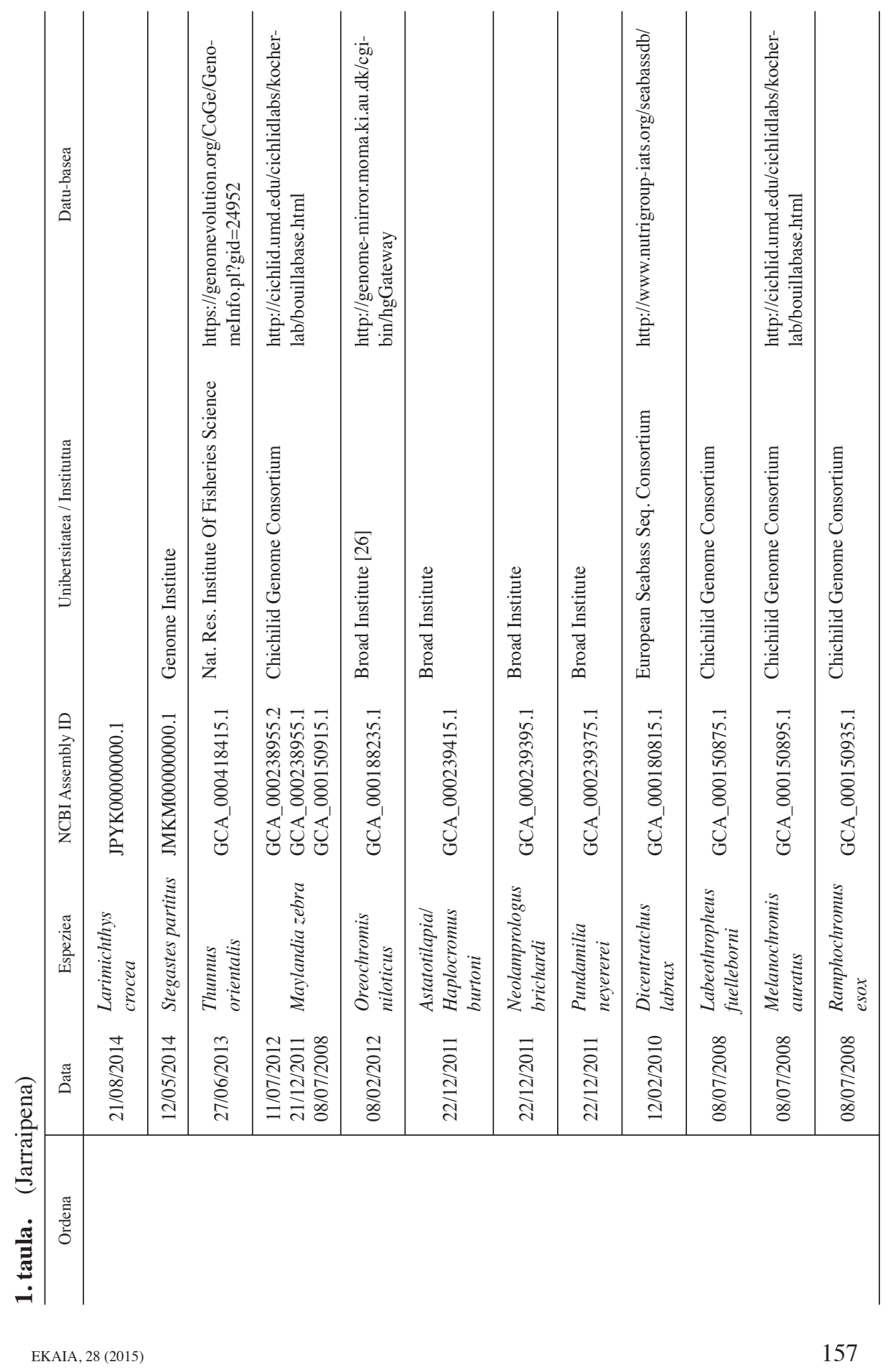




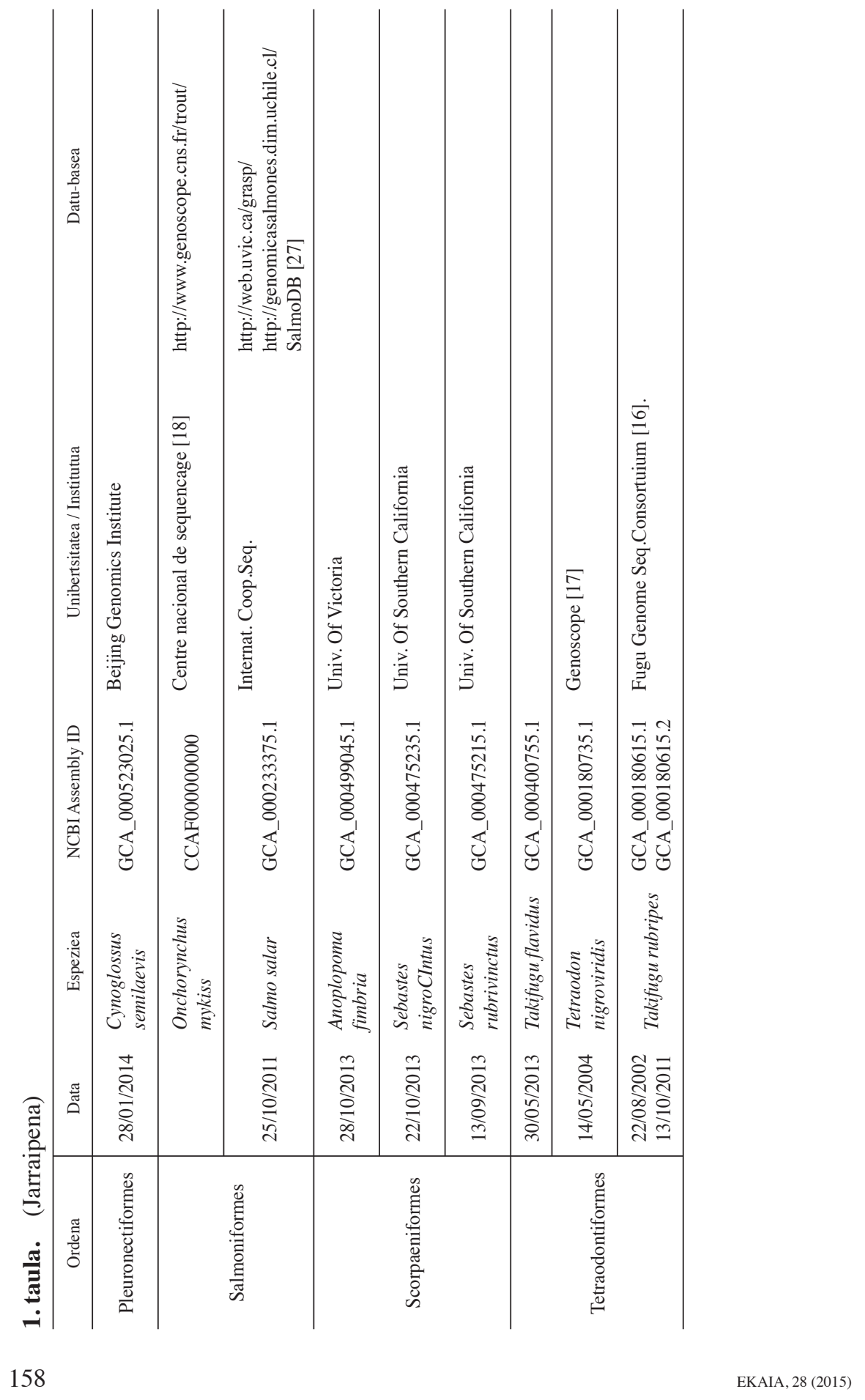


Deskodetutako arrainak: atzo, gaur eta bihar

\section{TRANSKRIPTOMA}

Zelulan, une jakin batean, gertatzen den gene-adierazpen multzoari transkriptoma deritzo, eta hau aldatzen doa zelulaz zelula, ehunez ehun, indibiduoz indibiduo, zein espeziez espezie. Aldaketa hauek guztiak zelularen, ehunaren, organismoaren, eta espeziearen barneko zein inguruko aldagaiek zehaztuko dituzte. Aldagai horiek aztertu eta zehazteko helburuarekin, transkriptomaren sekuentziazio saiakera ugari egin dira arrainetan eta ondorioz, emendatuz joan da espezie bakoitzaren mRNA sekuentzia ezberdinen kopurua zein berauen gaineko informazioa.

Aurretik esan bezala, sekuentziazio masiboen aurretik, beste sekuentziazio metodo batzuk egon dira, besteak beste, ESTak sekuentziatzeko programak, klonazioan eta Sanger sekuentziazio metodoan oinarritzen direnak. Honela, NCBI datu-baseko EST sekuentzien atalean, 2014ko martxoan, «actinopterygii» terminoa bilatuz gero, 5.612.243 sarrera lortzen ziren, lehenengo hamar arrain espezieen sailkapena hurrengoa izanik (parentesien artean EST kopurua adierazi da): Danio rerio (1.488.339), Oryzias latipes (666.891), Salmo salar (498.245), Ictalurus punctatus (354.516), Oncorhynchus mykiss (287.565), Gasterosteus aculeatus (277.051), Pimephales promelas (258.504), Gadus morhua (257.218), Astyanax mexicanus (189.864), Ictalurus furcatus (139.475). Datuok, hezurdun arrainei buruz NCBIn dagoen EST informazio guztiaren \%79a osatzen dute. Gainontzekoa, 119 espezieren artean banatuta dago. Honek, agerian uzten du berriro arrainen talde ezberdinetan dagoen informazio eskasa, milako 4a. (1. irudia).

EST sekuentzia hauek guztiak, proiektu ezberdinak direla medio lortu dira. Adibidez, Pleurogene ${ }^{\circledR}$ deritzon nazioarteko proiektuan, Senegaleko mihi-arraina [38] eta Atlantikoko halibutaren, Hippoglossus hippoglossus, [39] ESTak sekuentziatu ziren. Norbegian, halibutaren egun bateko larba eta heldugabeen EST sekuentziazioa egin zen, eta beraz, lorturiko sekuentziak garrantzitsuak izan ziren garapeneko edo eta amarekiko espezifikoak ziren transkriptoak identifikatzeko [40]. Amuarraina eta izokinari dagokienez, bi espezie hauen ESTen datu-base bat plazaratu zen (http://genomicasalmones.dim.uchile.cl/; [41]). Bestelako espezieentzat, batez ere, arrantzan zein akuikulturan garrantzitsuak diren espezieentzat, badira EST sekuentziatze-programak, besteak beste, honelako espezieentzat: urraburua -Sparus aurata - (Birdgemap project, www.bridgemap.tuc.gr/index.htm [42]), lupia -Dicentrachus labrax - (BassMap project, www.bassmap.org and [43]), bakailua -Gadus morhua - (Codgene project, http://codgene.ca), katuarraina - Ictalurus punctatus - [44], Japoniako platuxa - Paralichthys olivaceus - [45], eta erreboiluarentzat —Scophthalmus maximus - [46].

EST asko ingelesezko «Sustractive Supression Hybridization» (SSH) edota «differentialy displayed RT-PCR» (ddRT-PCR) tekniken bidez lortu 
dira. Gaur egun, teknologia berriak sortu direlarik, ia alboraturik daude bi teknika horiek baina, oraindik ere haien inguruko lan ugari argitaratzen dira (2. taula). Adibidez, NCBIn argitaratutako azkeneko SSH liburutegia Carassius auratus karpa laranjarena da, 2014ko otsailean; lan horretan, karpa laranjak herpesvirus birusarekin zoldu zituzten, hildakoen eta bizirik iraun zuten karpen giltzurruneko transkiptomak elkarrekin konparatzeko. 2010. urtean argitaratutako beste lan batean berriz (dbEST Id: 66996805), barne belarriko transkriptomaren aldaketa aztertu zuten, izokinak (Salmo salar) lurrikara baten soinuarekin estresatu ondoren. Teknika hauek erabilita, hainbat gai aztertu izan dira: zoldurak, soinu-estresak, elikaduraren, kutsatzaileen eta anoxiaren eraginak, organismoaren garapen-fase ezberdinak, urtaroen aldaketak, eta beste hainbat (2. taula). Bestalde, SSH teknika erabiliz arrainetan argitaratu den azkeneko artikulua, (2014ko apirilak 25) Monopterus albus arroz-zelaietako aingira hermafroditari buruzkoa izan da. Lan honek, genero-aldaketan parte har dezaketen gene posibleak zerrendatzen ditu [47].

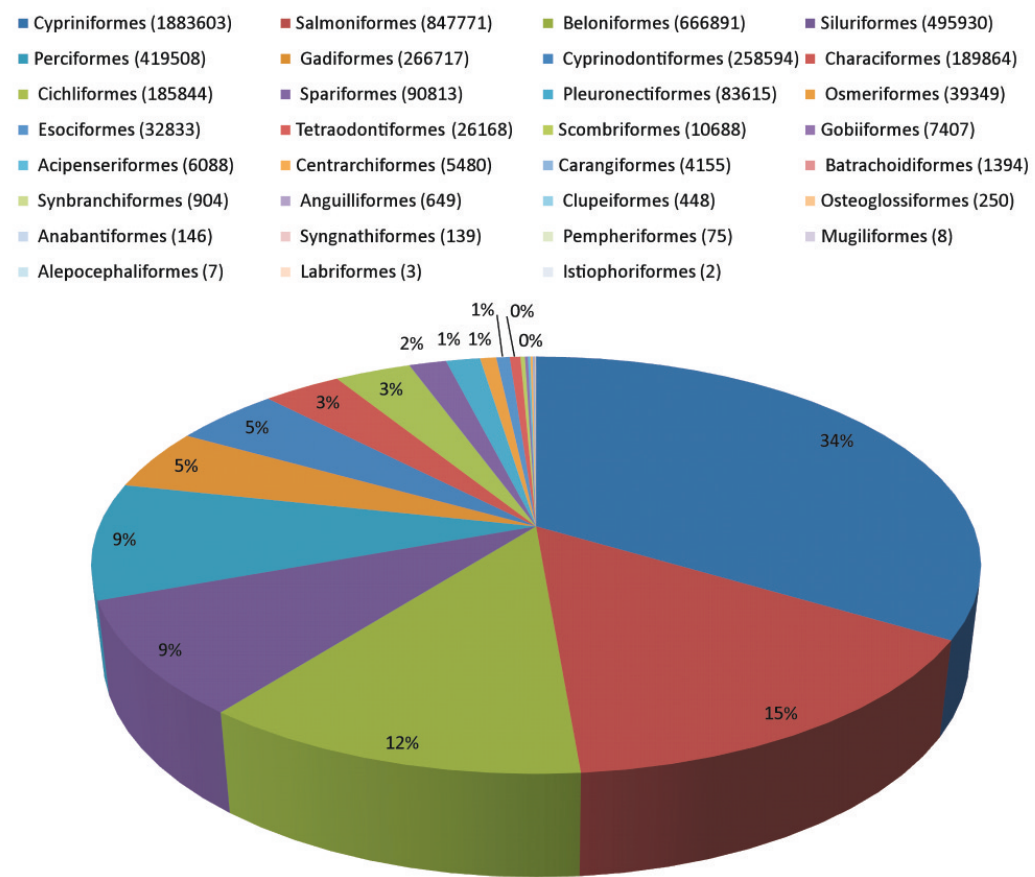

1. irudia. NCBIko EST datubasean «Actinopterygii» bilaketa egin ondoren, arrainen ordenaren araberako EST sarrera kopuruen banaketa adierazita dago (ehunekotan, \%). Orden bakoitzaren ondoan, sarrera kopurua adierazita dago da parentesi artean. 
2. taula. Estimulu ezberdinen eragina aztertzeko arrain espezie ezberdinetan egindako cDNA liburutegiak.

\begin{tabular}{|c|c|c|c|}
\hline Espeziea & Liburutegia & Aldagaiak & Erreferentzia \\
\hline \multirow{2}{*}{ Anguilla anguilla } & SSH & dimetilbenz $[a]$ antrazenoa & [48] \\
\hline & SSH & Gazitasunarekiko moldaera & [49] \\
\hline Aristichthys nobilis & SSH & erantzuna parasito bati & [50] \\
\hline \multirow{3}{*}{ Carassius auratus } & SSH & Garapena & [51] \\
\hline & SSH & Hipoxia & [52] \\
\hline & SSH & Tenperatura & [53] \\
\hline Carassius auratus gibelio & SSH & Immunitate-erantzuna & [54] \\
\hline Clarias batrachus & SSH & Hipoxia & [55] \\
\hline Chionodraco hamatus & dd RT-PCR & $\mathrm{Cd}$ & [56] \\
\hline Conger myriaster & SSH & Erantzun immunea & [56] \\
\hline Coregonus lavaetus & dd-RT-PCR & Benzo $[a]$ pirenoa & [58] \\
\hline Cynoglossus semilaevis & SSH & Sexu-ezberdintasunak & 59] \\
\hline \multirow{2}{*}{ Cyprinidon variegatus } & dd RT-PCR & Konposatu estrogenikoak & {$[60-61]$} \\
\hline & SSH & Cd eta hipoxia & {$[62]$} \\
\hline \multirow{4}{*}{ Cyprinus carpio } & SSH & PFOS & [63] \\
\hline & SSH & Disrupzio endokrinoa & [64] \\
\hline & SSH & Erantzun immunea & [65] \\
\hline & SSH & dietako eta ur emariko $\mathrm{Cd}$ & [66] \\
\hline \multirow{2}{*}{ Dicentrarchus labrax } & SSH & Zelaiko azterketa & [67] \\
\hline & SSH & Gazitasunarekiko moldapena adaptazioa & [68] \\
\hline Epinephelus awoara & SSH & Erantzun immunea & [69] \\
\hline Epinephelus coioides & SSH & Erantzun immunea & [70] \\
\hline \multirow{4}{*}{ Fundulus heteroclitus } & dd RT-PCR & Zelaiko azterketa & [71] \\
\hline & dd RT-PCR & Antrazenoa & [72] \\
\hline & SSH & Artsenikoa & [73] \\
\hline & SSH & Pirenoa & [74] \\
\hline \multirow[t]{2}{*}{ Gadus morhua } & SSH & Jakia & [75] \\
\hline & SSH & Erantzun immunea & [76-78] \\
\hline \multirow{2}{*}{ Gasterosteus aculeatus } & SSH & $\mathrm{EE} 2, \mathrm{Cu}$ eta di-benz $(\mathrm{a}, \mathrm{h})$ antrazenoa & [79] \\
\hline & SSH & Dibenzantrazenoa, oestradiola & [80] \\
\hline Leporinus macrocephalus & dd RT-PCR & Sexu-ezberdintasunak & [81] \\
\hline Liza aurata & SSH & Zelaiko azterketa & {$[82$} \\
\hline
\end{tabular}


2. taula. (Jarraipena)

\begin{tabular}{|c|c|c|c|}
\hline Espeziea & Liburutegia & Aldagaiak & Erreferentzia \\
\hline \multirow{3}{*}{ Micropterus salmoides } & dd RT-PCR & Estradiola & [83] \\
\hline & dd-RT-PCR & Paper-fabrika efluentea & [84] \\
\hline & SSH & Dihydrotestosterona, 11-ketotestosterona & [85] \\
\hline Onchorhynchus mykiss & SSH & Erantzun immunea & [86-89] \\
\hline Onchorhynchus tshawytscha & SSH & Erantzun immunea & {$[90]$} \\
\hline Oreochromis mossambicus & SSH & Estres-erantzuna & [91] \\
\hline \multirow{2}{*}{ Oreochromis niloticus } & dd RT-PCR & Lindanoa & [92] \\
\hline & dd RT-PCR & Sexu-ezberdintasuna & [93] \\
\hline \multirow{2}{*}{ Oryzias laetipes } & SSH & TCDD & [94] \\
\hline & SSH & Diazinona & [95] \\
\hline Osmerus mordax & SSH & Urtaeroen aldaketa & [96] \\
\hline Paralichtys olivaceus & $\mathrm{SSH}$ & Erantzun immunea & [97] \\
\hline Pimephales promelas & SSH & Estradiola & {$[98$} \\
\hline Pimephales promelas & SSH & RDX & [99] \\
\hline \multirow{4}{*}{ Platichthys flesus } & SSH & Adaptazioa & [100] \\
\hline & SSH & Pestiziden nahasketa & {$[101]$} \\
\hline & SSH & $\mathrm{Cd}$ & [102] \\
\hline & SSH & Toxiko-ereduak & [103] \\
\hline Plecoglossus altivelis & SSH & Erantzun immunea & {$[104]$} \\
\hline Pleuronectes americanus & SSH & Nonilfenola & [105] \\
\hline Pleuronectes platessa & SSH & EE2 & [106] \\
\hline Pomatochistus minutus & $\mathrm{SSH}$ & $17 \alpha$-etiniloestradiola & {$[107]$} \\
\hline \multirow{2}{*}{$\begin{array}{c}\text { Pseudopleuronectes } \\
\text { americanus }\end{array}$} & SSH & $\mathrm{Cr}(\mathrm{IV})$ & [109] \\
\hline & SSH & Zelaiko azterketa & {$[110-111]$} \\
\hline Pseudosciaena crocea & $\mathrm{SSH}$ & Erantzun immunea & {$[112-113]$} \\
\hline \multirow{2}{*}{ Salmo salar } & SSH & Erantzun immunea & [114] \\
\hline & SSH & Nonilfenola; tetraklorobisfenola & {$[115]$} \\
\hline Sarotherodon melanother & SSH & Gazitasunarekiko adaptazioa & [116] \\
\hline Solea senegalensis & $\mathrm{SSH}$ & Kutsatzaileak & {$[117]$} \\
\hline \multirow{3}{*}{ Sparus aurata } & dd-RT-PCR & Erantzun immunea & [118-119] \\
\hline & SSH & Erantzun immunea & [120] \\
\hline & SSH & Kutsatzaileak & [121] \\
\hline Triakis scyllia & SSH & Erantzun immunea & {$[122]$} \\
\hline Tursiops truncatus & $\mathrm{SSH}$ & Kutsatzaileak & {$[123]$} \\
\hline
\end{tabular}




\section{SEKUENTZIAZIO TEKNOLOGIA BERRIEN ERAGINA TRANSKRIPTOMIKAN}

Gaur egun, sekuentziazio esparruan iraultza ekarri dute hainbat teknikek: Roche 454 GS System ${ }^{\circledR}$, Applied Biosystems SOLiD® System, Illumina Genome Analyzer $\AA$, Helicos Heliscope ${ }^{\circledR}$, Complete Genomics ${ }^{\circledR}$, Pacific Biosciences SMRT®, Ion Torrent edo Oxford Nanopore. Hauetako batzuk jada gutxi erabiltzen dira, baina haiei esker lortu da organismo ugariren molekula mailako informazioa. Horrela, ingelesezko «Sequence Read Archive (SRA)» NCBIko datu-basean NGS bidez lortutako emaitzen datuak bildu dira. Bertan, 2014ko urrian, «Actinopterygii» terminoa bilatuz gero, 17.652 sarrera lor zitezkeen, eta haietatik, 3.922 RNA sekuentziazioei (RNA-seq) zegozkien. RNAseq-en artean, 21 arrain Orden ezberdin topa zitezkeen (2. irudia) eta 241 espezie ezberdin (batzuk espezie hibridoak dira); horien artean gehienak Cyprinidontiforme ordenekoak dira. Aldiz, SRA emaitza gehien duen espeziea Cypriniforme ordenekoa da, Danio rerio zebrarraina; izan ere, arrain eredua da zientzian. Guztira, SRA bidez sekuentziatutako espezie kopurua milako 7ra igotzen da, RNA sekuentziazioa milako 5a izanik. Nahiz eta arrain espezieen \%40a Perciforme-ak izan, 3. dago NCBI SRA datu-basean espezie gehien dituztenen artean (2. irudia).

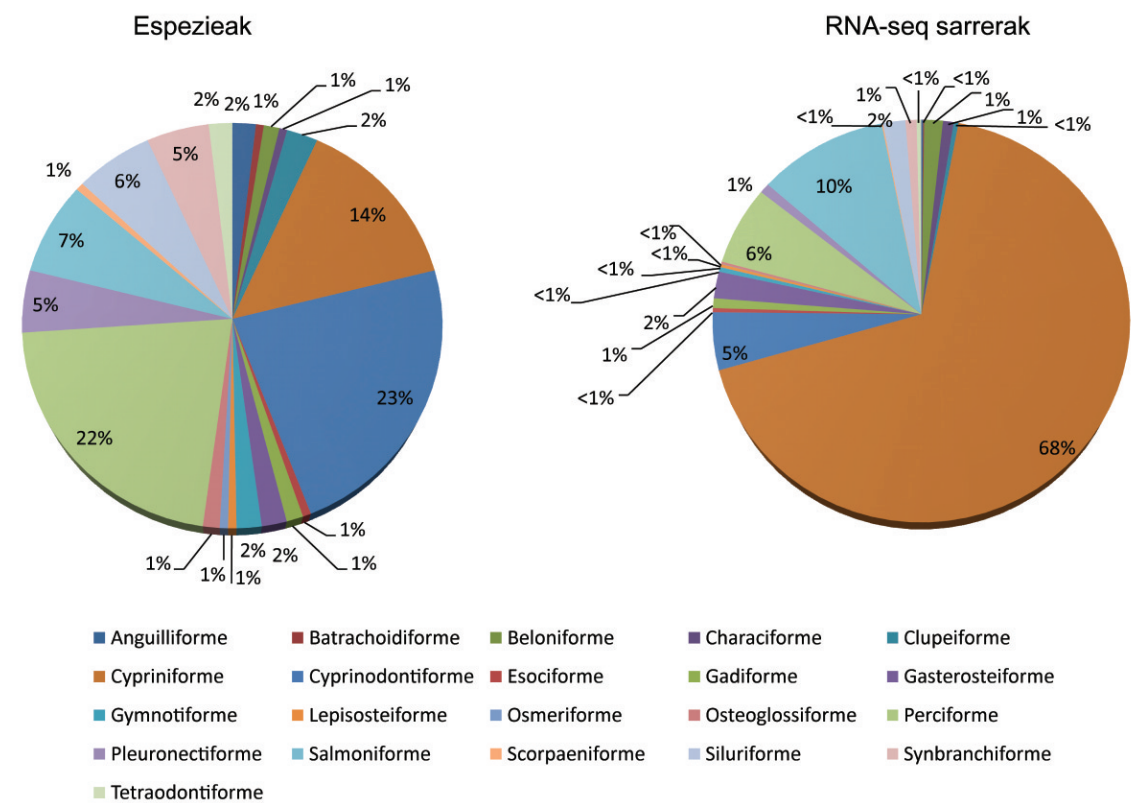

2. irudia. NCBIko SRA datu-basean 2014ko urrian RNA-datuen gaineko «Actinopterygii» arrainen banaketa. Ezkerreko grafikoan ikus daiteke arrainen Orden ezberdinen araberako espezie kopuruaren banaketa (\%). Eskubiko grafikoan ikus daiteke ordea arrainen Orden ezberdinen araberako RNA sarrera kopurua. 
2008an argitaratu zen eredu ez den lehenengo arrainaren transkriptomaren sekuentziazioa Rocheren 454 metodoari esker. Orduan, Micropterus salmoides lupia beltzaren gibeleko eta gonadako transkriptoma sekuentziatu zen [124]. Harrez geroztik, genomak eta transkriptomak tantaz tanta joan dira plazaratzen. 2009an, esaterako, gaztelerazko «licodes» arrainaren (Zoarces viviparus) gibeleko transkriptoma [125], eta poliploidea den Acipes fulvescens esturoiaren gonadetako transkriptoma [126]. Beranduago, metodo bera erabiliz, sekuentzia andana plazaratu da (berriak aurkitzeko http://454.com/publications/); hauek dira espezieak, besteak beste: Fundulus heteroclitus [127], Gadus morhua [128-129], Epinephelus coioides [130], Anguilla rostrata [131], Poecilia reticulata [132], Kriptolebias marmotatus [133], Oplegantus fascinates [134], Eptatretus burger, Scyliorhinus torazame eta Polypterus senegalus [135], Coregonuss spp. [136, 137], Perca flavescens [138], Sparus aurata [139-141], Scoptalmus maximus [142,143], Dicentrarchus labrax [144], Megalobrama amblycephala [145], Anguilla anguilla (EeelBase, [146, 147]), Notothenia coriiceps, Chaenocephalus aceratus, eta Pleuragramma antarcticum [148], Astyanax mexicanus [149], Syngnathus typhle [150], Hippoglossus hippoglossus [151], Solea solea [152], Lota lota [153], Anguilla japonica [154], eta Engraulis encrasicolus antxoari dagokiona [155].

Orain gutxi arte azterketa hauen guztien helburua sekuentzien karakterizazioa/identifikazioa izan da, eta sekuentzia horietatik, gene-dentsitate handiko mikroarraiak garatu dira [124-125] geneen zeharkako kuantifikazioak egiteko. Baina teknologia aurrera doan heinean, sekuentziazio teknika berriak eta hobeak ezagutzen doaz. Horrela, mikroarraiak alboratzen joan dira. Gaur egungo RNAren gaineko sekuentziazio zuzenak (RNAseq-ak) ahalbidetzen du gene sekuentzia bakoitza zenbat aldiz sekuentziatuta dagoen zenbatzea/estimatzea, eta honi gene-adierazpen digitala, ingelesezko «digital gene expression»(DGE) deitu zaio. Teknika berriek, sekuentzia kopurua zenbatzeaz gain, hainbat abantaila gehigarri dituzte, besteak beste, sentikortasun handiagoa, RNA kodetugabea aztertzeko gaitasun handiagoa, transkripto berriak eta isoforma berriak detektatzeko ahalmena, zelula bakar baten adierazpena aztertzeko ahalmena, SNPen aurkikuntza, gene-mapaketa hobea, etab. [156-159].

Qian eta lankideek 2013ko RNAseq laburpenean azpimarratu bezala [160], RNAseq azterketa arrainetan berria da eta horren inguruko argitalpenak orain ari dira plazaratzen; izan ere, lehenengoak 2010-11 bitartekoak dira. Lan berean, Qian eta lankideek, 2013. urtera arte zeuden RNAseq bidezko kuantifikazio analisiak bildu zituzten, hurrengo arloei erreparatuz: prozesu fisiologikoak, akuikultura, uretako toxikologia, eboluzio-biologia, immunologia eta garapen-biologia. Hala ere, gaur egun ekotoxikologian garrantzia duten gaiak aztertzen dituzten lan gutxi argitaratu dira. Adibidez, $F$. heteroclitus arrainaren enbrioi eta larbetan eragiten diren efektu agonis- 
Deskodetutako arrainak: atzo, gaur eta bihar

tak aztertu ziren hidrokarburo ariloen hartzailean [127]; horretarako geneprofil jakin batzuk aztertu zituzten, eta elkarrekin alderatu zituzten bromuro poliklorinatuez kutsaturiko ingurune jakinean bizi ziren arrainen populazioak eta kontrol gune batean bizi zirenak. Perca flavescens karpan ordea, agerian utzi zuten gibelak metal astunekin kutsaturiko ingurune batean garatzen duen erresistentzia [138]. Lan honetan, aztertu zuten kobre eta kadmio $(\mathrm{Cu}, \mathrm{Cd})$ tratamenduek, nola desorekatzen dituzten immunitate-sistema zein erretinol eta energia-metabolismoak. Horrez gain, RNAseq-ak, ahalbidetu zuen Cd kutsadura-gradienteak eragindako moldapena bidezko eboluzioa aztertzea, eta horrela adaptaziorako gene-profilak identifikatu zituzten [138]. Oryzias melastigma itsasoko medaka arrainean ordea, azido perfluoroktanoiko (PFOA) kutsatzaile organiko pean gertatzen diren gene mailako aldaketak aztertu ziren DGE bidez eta ondorioztatu zuten PFOAk modu ezberdinean erregulatzen dituela enbrioien efektu neurologikoan, mitokondrioen disfuntzioan eta proteina zein lipidoen metabolismoan parte hartzen duten geneak [161]. Bestalde, nitritoen kontzentrazio ezberdinek mutur zapaleko Megalobrama amblycephala bisiguaren gibelean eragin ditzaketen efektuak aztertu dituzte, eta estres oxidatiboa, hipoxia histotoxikoa eta zelularen hilkortasunarekin zerikusia duten geneak antzeman dituzte DGE bidez [162]. Landa-ikerketetak bilatu nahi izanez gero, aurkituko dugu lota arraina (Lota lota) toxikogenomika azterketa baterako erabili zela, metal astunez gain, batez ere, brominaturiko sustantzia kimikoak dituen Mjøsa lakuan [153]. Ikerketa honetan, orain arte erdi alboratuta zegoen SSH liburutegi teknikekin osatu zuten transkriptoma mailako ikerketa, eta horrela, DGE bidez karakterizatu zuten Lota lota arrainaren transkriptoma; bertan bereziki, ondorioztatu zuten kutsatzaileek eragindako hartzaile nuklearren bidezko transkripzioaren aktibazioa gertatzen dela, eta aktibazio horrek gibeleko estress oxidatiboa eragin dezakeela. Hala ere, egileek aldarrikatzen dute fenotipoaren eta analisi molekularren arteko harremana aurkitu behar dela [153]. Aldarrikapen hau beste hainbeste heda daiteke, adibidez metalen tolerantzia handia duten Salmo trutta populazioen esparrura. Horrela, ondorioztatu dute aipaturiko gune horietan bizitzea baimentzen dieten bidezidor metabolikoak daudela baina ezin izan dute zehaztu benetako adaptazioa edo egoeraren aurreko erantzuna den, lotura bera aztertzea falta baita [163].

\section{ETORKIZUNA ETA ONDORIOAK}

Azaldu moduan, arrainen gene-kodearen ezagutza azken hamarkadan esponentzialki emendatu da. Orokorrean, arrainen genoma ezagutzeak lagundu diezaguke hainbat arlotan diharduten bidezidorrak ulertzen: garapenaren prozesu biologikoak, gaixotasunen disfuntzioak, immunitate-ezagutzak, elikadura, ingurumeneko aldaketen aurreko adaptazioa, ernalketa eta eboluzioa [164]. 
Informazio-oparotasun honek zenbat eta arrain familia ezberdin gehiago barneratu orduan eta eboluzioari buruzko informazio gehiago edukiko da. Zenbat eta filogeniako hutsune gehiago bete, eta sekuentziatu, orduan eta errazago detektatuko dira eboluzio-presioagatik gertatutako fenomenoak. Gaur egun, ikertzaileak, ekotoxikologoak batez ere, tematurik daude oso, estres fisiko-kimiko ezberdinek edota beraien multzoek arrainetan duten eragina zehazten, interes handikoa izan baitaiteke, akuikulturan eta ingurumen toxikologian. Baina kutsadura horrek eragin dezakeen presioaren ondorioz, populazioetan gertatzen diren gene-mailako adaptazio-aldaketa ez dira aztertu. 2011. urteaz geroztik garatzen ari da joera berri hau. Garai batean, oztopo fisikoak izan ohi ziren soilik organismo bat adaptatu eta eboluzionatzea eragiten zutenak, baina gaur egun, jakin badakigu, oztopo horien artean kutsadura ere badugula; izan ere, nabarmen alda daiteke kutsaduraren eragina kilometro gutxi batzuetan edo medio batetik bestera. Beraz, «eboluzio-toxikologia» deritzon arlo berri hau kutsadurak eragin ditzakeen gene mailako aldaketetan oinarritzen da; populazioan nola barreiatzen diren aztertzen da, eta horrela, erresistentzia edo sentikortasuna garatzen dutenentz zehazten dute.

Arrainen genoma eta transkriptomaren sekuentziazioek badakarte molekula mailako azterketetarako tresnak garatzea, hala nola, biomarkatzaile espezifiko berriak, edota mikroarraiak edo ingelesezko «digital gene expression» edo adierazpen digitalak. Hauek, besteak beste, ahalbidetuko dute ur-inguruko aldagai fisiko-kimikoek animalietan nola eragiten duten aztertzea, kuantifikatzea, eta ulertzea; era berean, aldaketek ekosisteman duten eragina estrapolatzen lagunduko digu. Arazo nagusi bat dago: gene-aldaketek adierazten dutena arrainaren osasunarekin uztartzen asmatu ezinik jarraitzen dugu. Hau da, behar-beharrezkoa da molekula mailan islatzen dena maila biologikoan esangarria ote den ikertzea. Era berean, zehaztu beharrekoa da RNAseq berrien emaitzek plazaratzen dituzten bidezidorren erantzun-hipotesiek, ekotoxikologia, immunologia zein fisiologia-azterketetan fisiologikoki zein fenotipikoki garrantzia dutenentz.

\section{BIBLIOGRAFIA}

[1] NELSON, J.S. «Fishes of the world», 4th ed. John Wiley \& Sons, Inc.: Hoboken (NY), USA, 2006; p. 601.

[2] GREGORY, T.R. 2012. « Animal Genome Size Database». Available at ttp://www.genomesize.com.

[3] POSTLETHWAIT, J.H.; WOODS, I.G.; NGO-HAZELETT, P.; YAN Y.L.; KELLY, P.D.; CHU, F.; HUANG H, HILL FORCE A. eta TALBOT WS. 2000. «Zebrafish comparative genomics and the origins of vertebrate chromosomes». Genome Research, 10, 1890-1902. 
Deskodetutako arrainak: atzo, gaur eta bihar

[4] FRENKEL, S.; KIRZHNER, V. eta KO, A. 2012. «Organizational heterogeneity of vertebrate genomes». Plos ONE, 7(2): e32076.

[5] SANGER, F.; NICKLEN, S. eta COULSON, A.R. 1977. «DNA sequencing with chain-terminating inhibitors. (DNA polymerase/nucleotide sequences/ bacteriophage 4X174).» Proc. of the National Academy of Sciences, 74(12): 5463-5467.

[6] HYMA E.D. 1988.« A new method of sequencing DNA». Anal. Biochem. 174, 423-436.

[7] REINARTZ, J.; BRUYNS, E.; LIN, J.Z.; BURCHAM, T.; BRENNER, S.; BOWEN, B.; KRAMER, M. eta WOYCHIK, R. 2002. «Massively parallel signature sequencing (MPSS) as a tool for in-depth quantitative gene expression profiling in all organism». Briefings in Functional Genomics \& Proteomics, 1 (1): 95-104.

[8] METZKER, M.L. 2010. «Sequencing technologies - the next generation». Nature Reviews Genetics, 11: 31-46.

[9] COCHRANE, G.R. eta GALPERIN, M.Y. 2010. «The 2010 Nucleic Acids Research Database Issue and online Database Collection: a community of data resources.» Nucleic Acids Research, 38 (1): D1-D4.

[10] SMITH, J.J.; KURAKU, S.; HOLT, C.; SAUKA-SPENGLER, T.; JIANG, N.; CAMPBELL, M.S. et al. 2013 «Sequencing of the sea lamprey (Petromyzon marinus) genome provides insights into vertebrate evolution». Nature Genetics 45,415-421.

[10] MEHTA, T.K.; RAVI, V.; YAMASAKI, S.; LEE, A.P.; LIAN, M.M.; TAY, B.; TOHARI, S.; YANAI, S.; TAY, A.; BRENNER, S. eta VENKATESH, B. 2013. «Evidence for at least six Hox clusters in the Japanese lamprey (Lethenteron japonicum). » Proc. Natl. Acad. Sci. USA. 110: 16044-16049.

[12] VENKATESH, B.; KIRKNESS, E.F.; LOH, Y.H. et al. 2007. «Survey Sequencing and Comparative Analysis of the Elephant Shark (Callorhinchus milii) Genome». PLOS Biology 5 (4): e 101.

[13] WANG, Q.; KING, B.; ARIGHI, C.; HUANG, H.; KAPLAREVIC, M.; KINGHAM, B.; VINCENT, J.; RENDINO, M.F.; DAHN, R.D.; MATTINGLY, C.; CHICHESTER, C.; FUEYO, J.; THOMAS, W. eta KWU, C.H. 2010. «Skate Genome Project: Cyber-Enabled Research and Workforce Development» National IDeA Symposium of Biomedical Research Excellence Symposium, Bethesda, MD, June 16-18, 2010.

[14] KING, B.L. 2011.«The Genome Sequence Project for The Little Skate, Leucoraja erinacea», 2011 Annual North East Cyberinfrastructure Consortium Meeting, Orono, ME, March 15, 2011.

[15] WYFFELS, J.L.; KING, B.; VINCENT, J.; CHEN, C.; WU, C.H. eta POLSON, S.W. 2014. «SkateBase, an elasmobranch genome project and collection of molecular resources for chondrichthyan fishes». Research 3:191.

[16] APARICIO, S.; CHAPMAN, J.; STUPKA, E.; PUTNAM, N.; CHIA, J.M.; DEHAL, P.; CHRISTOFFELS, A.; RASH, S. et al. 2002. «Whole-genome 
shotgun assembly and analysis of the genome of Fugu rubripes». Science, 297: 1301-1310.

[17] JAILLON, O.; AURY, J.M.; BRUNET, F.; PETIT, J.L.;STANGETHOMANN, N.; MAUCELI, E.; BOUNEAU, L.; FISCHER, C. et al. 2004. «Genome duplication in the teleost fish Tetraodon nigroviridis reveals the early vertebrate proto-karyotype». Nature, 431: 946-957.

[18] BERTHELOT, C.; BRUNET, F.; CHALOPIN, D.; JUANCHICH, A.; BERNARD, M.; NOËL, B.; BENTO, P.; DASILVA, C. et al. 2014. «The rainbow trout genome provides novel insights into evolution after whole-genome duplication in vertebrates». Nature Communications, DOI : 10.1038/ ncomms4657.

[19] ZHANG, Y.; WANG, S.; LI, J.; ZHANG, X.; JIANG, L.; XU, P. et al. 2013. "Primary genome scan for complex body shape-related traits in the common carp Cyprinus carpio.» Journal of fish biology. 82(1):125-40.

[20] ZHANG, X.; ZHANG, Y.; ZHENG, X.; KUANG, Y.; ZHAO, Z.; ZHAO, L. et al. 2013.«A consensus linkage map provides insights on genome character and evolution in common carp (Cyprinus carpio L.).» Marine biotechnology. 15(3):275-312.

[21] ZHAO, L.; ZHANG, Y.; JI, P.; ZHANG, X.; ZHAO, Z.; HOU, G. et al. 2013.« A dense genetic linkage map for common carp and its integration with a BAC-based physical map. » PLoS One. 8(5):e63928.

[22] RONDEAU, E.B.; MINKLEY, D.R.; LEONG, J.S.; MESSMER, A.M.; JANTZEN, J.R. et al. 2014. «The genome and linkage map of the northern pike (Esox lucius): conserved synteny revealed between the salmonid sister group and the neoteleostei.»PLOS ONE 9(7): e102089.

[23] JONES, F.C.; CHAN, Y.F.; SCHMUTZ, J.; GRIMWOOD, J.; BRADY, S.D.; SOUTHWICK, A.M.; ABSHER, D.M.; MYERS, R.M.; REIMCHEN, T.E.; DEAGLE, B.E.; SCHLUTER, D. eta. KINGSLEY D.M. 2012 . «A genome-wide SNP genotyping array reveals patterns of global and repeated species pair divergence in sticklebacks». Current Biology 22:83-90.

[24] LOH, Y.H.E.; KATZ, L.S.; MIMS, M.C.; KOCHER, T.D.; VI, S.V. eta STREELMAN, J.T. 2008. "Comparative analysis reveals signatures of differentiation amid genomic polymorphism in Lake Malawi cichlids». Genome Biology, 9:R113.

[26] GUYON, R.; RAKOTOMANGA, M.; AZZOUZI, N.; COUTANCEAU, J.P.; BONILLO, C.; D'COTTA, H.; PEPEY, E. et al. 2012. «A high-resolution map of the Nile tilapia genome: a resource for studying cichlids and other percomorphs». BMC Genomics. 6;13:222.

[25] SHIN, S.C.; AHN, D.H.; KIM,S.J.; PYO, C.W.; LEE, H.; KIM, M.; LEE, J.; LEE, J.E.; DETRICH, H.W.; POSTLETHWAIT, J.H, EDWARDS, D.; LEE, S.G.; LEE, J.H. eta PARK, H. 2014. «The genome sequence of the Antarctic bullhead notothen reveals evolutionary adaptations to a cold environment. Genome Biology, 15:468. 
Deskodetutako arrainak: atzo, gaur eta bihar

[27] DAVIDSON, W.S.; KOOP, B.F.; JONES, S.J.M.; ITURRA, P.; VIDAL, R.; MAASS, A.; JONASSEN, I.; LIEN, S. eta OMHOLT, S. 2010. «Sequencing the genome of the Atlantic salmon (Salmo salar)». Genome Biology, 11:403.

[28] KASAHARA, M.; NARUSE, K.; SASAKI, S.; NAKATANI, Y.; QU, W.; AHSAN, B.; YAMADA, T.; NAGAYASU, Y.; DOI, K.; KASAI, Y.; JINDO, T.; KOBAYASHI, D.; SHIMADA, A.; TOYODA, A.; KUROKI, Y. et al. 2007. «The medaka draft genome and insights into vertebrate genome evolution». Nature, 447: 714-719.

[29] AHSAN, B.; KOBAYASHI, D.; YAMADA, T.; KASAHARA, M.; SASAKI, S.; SAITO, T.L.; NAGAYASU, Y.; DOI, K.; NAKATANI, Y.; QU, W.; JINDO, T.; SHIMADA, A. et al. 2008. «UTGB/medaka: genomic resource database for medaka biology». Nucleic Acids Research, 36: D747D752.

[30] STAR, B.; NEDERBRAGT, A.J.; JENTOFT, S.; GRIMHOLT, U.; MALMSTRØM, M.; GREGERS, T.F.; ROUNGE, T.B.; PAULSEN, J. et al. 2011. «The genome sequence of Atlantic cod reveals a unique immune system». Nature 477, 207-210.

[31] AMEMIYA, C.T.; ALFÖLDI, J.; LEE, A.P.; FAN, S.; PHILIPPE, H.; MACCALLUM, I.; BRAASCH, I.; MANOUSAKI, T. et al. 2013. «The African coelacanth genome provides insights into tetrapod evolution.»Nature 496, 311-316.

[32] SCHARTL, M.; WALTER, R.B.; SHEN, Y.; GARCIA, T.; CATCHEN, J.; AMORES, A.; BRAASCH, I.; CHALOPIN, D. et al. 2013.«The genome of the platyfish, Xiphophorus maculatus, provides insights into evolutionary adaptation and several complex traits». Nat Genet. 45(5):567-72.

[33] ZHANG, Z.; WANG, Y.; WANG, S.; LIU, J.; WARREN, W.; MITREVA, M. eta WALTER, R.B. 2011. «Transcriptome Analysis of Female and Male Xiphophorus maculates.» PLOS ONE, 6(4): e18379.

[34] MCGAUGH, S.E.; GROSS J.B, AKEN, B.; BLIN, M.; BOROWSKY, R.; CHALOPIN, D.; HINAUX, H.; JEFFERY, W.R.; KEENE, A.; MA, L.; MINX, P.; MURPHY, D.; O'QUIN, K.E.; RÉTAUX, S.; ROHNER, N.; SEARLE, S.M.; STAHL, B.A.; TABIN, C.; VOLFF, J.N.; YOSHIZAWA, M. eta WARREN, W.C. 2014. «The cavefish genome reveals candidate genes for eye loss.» Nat Commun. 5:5307. doi: 10.1038/ncomms6307.

[35] AMORES, A.; CATCHEN, J. M.; FERRARA, A.; FONTENOT, Q. eta POSTLETHWAIT, J. H. 2011. «Genome evolution and meiotic maps by massively parallel DNA sequencing: spotted gar, an outgroup for the teleost genome duplication». Genetics 188: 799-808.

[36] LU, J.; PEATMAN, E.; YANG, Q.; WANG, S.; HU, Z.; REECY, J.; KUCUKTAS, H. eta LIU, Z. 2010. «The catfish genome database cBARBEL: an informatic platform for genome biology of ictalurid catfish». Nucleic Acid Research. 1-7, doi:10.1093/nar/gkq76.

[37] BERNARDI, G.; WILEY, E.O.; MANSOUR, H.; MILLER, M.R.; ORTI, G.; HAUSSLER, D.; O’BRIEN, S.J.; RYDER, O.A. eta VENKATESH, B. 
2012. «The fishes of Genome 10K». Marine Genomics, doi:10.1016/j. margen.2012.02.002.

[38] CERDÀ, J.; MERCADÉ, J.; LOZANO, J.J.; MANCHADO, M.; TINGAUD-SEQUEIRA, A.; ASTOLA, A.; INFANTE, C. et al. 2008." Genomic resources for a commercial flatfish, the Senegalese sole (Solea senegalensis): EST sequencing, oligo microarray design, and development of the bioinformatic platform Soleamold». BMC Genomics, 9: 508.

[39] DOUGLAS, S.E.; KNICKLE, L.C.; KIMBALL, J. eta REITH, M.E. 2007. «Comprehensive EST analysis of Atlantic halibut (Hippoglossus hippoglossus), a commercially relevant aquaculture species». BMC Genomics, 8, 144

[40] BAI, J.; SOLBERG, C.; FERNANDES, J.M.O. eta JOHNSTON, I.A. 2007. «Profiling of maternal and developmental-stage specific mRNA transcripts in Atlantic halibut Hippoglossus hippoglossus.» Gene, 386: 202-210.

[41] DI GÉNOVA, A.; ARAVENA, A.; ZAPATA, L.; GONZÁlEZ, M.; MAASS, A. eta ITURRA, P. 2011. «SalmonDB: a bioinformatics resource for Salmo salar and Oncorhynchus mykiss.» Database, bar050 doi: 10.1093/ database/bar050.

[42] LOURO, B.; PASSOS, A.L.S.; SOUCHE, E. L.; TSIGENOPOULOS, C.; BECK, A.; LAGNEL, J.; BONHOMME, F.; CANCELA, L.; CERDÀ, J.; CLARK, M.S.; LUBZENS, E.; MAGOULAS, A.; PLANAS, J.V.; VOLCKAERT, F. A.M.; REINHARDT, R. eta CANARIO, A.V.M. 2010. « Gilthead sea bream (Sparus auratus) and European sea bass (Dicentrarchus labrax) expressed sequence tags: Characterization, tissue-specific expression and gene markers». Marine Genomics, 3 (3-4), 179-191. 10.1016/j.margen. 2010.09.005.

[43] CHINI, V.; RIMOLDI, S.; TEROVA, G.; SAROGLIA, M.; ROSSI, F.; BERNARDINI, G. eta GORNATI, R. 2006. «EST based identification of genes expressed in the liver of adult seabass (Dicentrarchus labrax, L.)». Gene, 376: 102-106.

[44] JU, Z.; KARSI, A.; KOCABAS, A.; PATTERSON, A.; LI, P.; CAO, D.; DUNHAM, R. eta LIU, Z. 2000. «Transcriptome analysis of channel catfish (Ictalurus punctatus): genes and expression profile from the brain». Gene, 261(2): 373-382.

[45] KUROBE, T.; YASUIKE, M.; KIMURA, T.; HIRONO, I. eta AOKI, T. 2005. «Expression profiling of immune-related genes from Japanese flounder Paralichthys olivaceus kidney cells using cDNA microarrays». Developmental Comparative Immunology, 29(6), 515-523.

[46] PARDO, B.G.; FERNÁNDEZ, C.; MILLÁN, A.; BOUZA, C.; VÁZQUEZLÓPEZ A.; VERA M.; ALVAREZ-DIOS, J.A.; CALAZA, M.; GÓMEZTATO, A.; VÁZQUEZ, M.; CABALEIRO, S.; MAGARIÑOS, B.; LEMOS, M.L.; LEIRO, J.M. eta MARTÍNEZ, P. 2008. «Expressed sequence tags (ESTs) from immune tissues of turbot (Scophthalmus maximus) challenged with pathogens». BMC Veterinary Research, 4:37 doi:10.1186/1746-61484-37. 
[47] QU, X.; JIANG, J.; SHANG, X.; CHENG, C.; FENG, L. eta LIU, Q. 2014. «Construction and analysis of gonad suppression subtractive hybridization libraries for the rice field eel, Monopterus albus». Gene.540(1):20-5.

[48] NOGUEIRA, P.; LOURENÇO, J.; RODRIGUEZ, E.; PACHECO, M.; SANTOS, C.; ROTCHELL, J.M. eta MENDO, S. 2009. «Transcript profiling and DNA damage in the European eel (Anguilla anguilla L.) exposed to 7,12-dimethylbenz[a]anthracene». Aquatic Toxicology, 94: 123-130.

[49] KALUJNAIA, S.; MCWILLIAM, I.S.; ZAGUINAIKO, V.A.; FEILEN, A.L.; NICHOLSON, J.; HAZON, N.; CUTLER, C.P.; BALMENT, R.; COSSINS, A.R.; HUGHES, M. eta CRAMB, G. 2007. «Salinity adaptation and gene profiling analysis in the European eel (Anguilla anguilla) using microarray technology. General \& Comparative Endocrinology, 152: 274-280.

[50] CUI, Z.; ZHANG, K.; QU, X. eta LIU, Q. 2011. «Construction of differentially expressed genes library of bighead carp (Aristichthys nobilis) exposed to microcystin-lr using SSH and expression profile of related genes». Fish \& Shellfish Immunology, 31(6): 746-53.

[51] WEN, J.; XIE, J. eta GUI, J. 2003. «cDNA cloning and characterization of a novel SNX gene differentially expressed in previtellogenic oocytes of gibel carp». Comparative Biochemistry \& Physiology, 136: 451-461.

[52] ZHONG, X.P.; WANG, D.; ZHANG, Y.B. eta GUI, J.F. 2009. «Identification and characterization of hypoxia-induced genes in Carassius auratus blastulae embryonic cells using suppression subtractive hybridization.» Comp Biochem Physiol B Biochem Mol Biol. 152(2):161-70.

[53] WANG, J.; WEI, Y.; LI, X.; XU, M. eta DAI, J. 2007. «Identification of differentially expressed genes from contaminant and thermal exposed goldfish Carassius auratus in Gaobeidian Lake in Beijing, China». Ecotoxicology. 16(7):525-32.

[54] XU, L.; PODOK, P.; XIE, J. eta LU, L. 2014. «Comparative analysis of differential gene expression in kidney tissues of moribund and surviving crucian carp (Carassius auratus gibelio) in response to cyprinid herpesvirus 2 infection». Arch Virol. 159(8):1961-74.

[55] MOHINDRA, V.; SINGH, A.; BARMAN, A.S.; TRIPATHI, R.; SOOD, N. eta LAL, K.K. 2012. «Development of EST derived SSRs and SNPs as a genomic resource in Indian catfish, Clarias batrachus.» Mol Biol Rep 39: 5921-31.

[56] CARGINALE, V.; CAPASSO, C.; SCUDIERO, R. eta PARISI, E. 2002. «Identification of cadmium-sensitive genes in the Antarctic fish Chionodraco hamatus by messenger RNA differential display». Gene, 16: 117-124.

[57] TSUTSUI, S.; IWAMOTO, T.; NAKAMURA, O. eta WATANABE, T. 2007. «LPS induces gene expression of interleukin-1 $\beta$ in conger eel (Conger myriaster) macrophages: First cytokine sequence within Anguilliformes». Fish \& Shellfish Immunology, 23: 911-916.

[58] BRZUZAN, P.; JURCZYK, L. eta FOKS, T. 2005. «Differential gene expression in benzo(a)pyrene exposed whitefish (Coregonus lavaretus)». Advances in Limnology, 60: 149-157. 
[59] SUN, Y.; ZHANG, Q.; QI, J.; CHEN, Y.; ZHONG, Q.; LI, C.; YU, Y.; LI, S. eta WANG, Z. 2010. «Identification of differential genes in the ovary relative to the testis and their expression patterns in half-smooth tongue sole (Cynoglossus semilaevis)». J. of Genetics \& Genomics, 37: 137-145.

[60] LARKIN, P.; KNOEBL, I. eta DENSLOW, N.D. 2003. «Differential gene expression analysis in fish exposed to endocrine disrupting compounds». Comparative Biochemistry \& Physiology, 136: 149-161.

[61] DENSLOW, N.D.; BOWMAN, C.J.; FERGUSON, R.J.; LEE, H.S.; HEMMER, M.J. eta FOLMAR, L.C. 2001. «Induction of gene expression in sheepshead minnows (Cyprinodon variegatus) treated with $17 \beta$-estradiol, diethylstilbestrol, or ethinylestradiol: the use of mRNA fingerprints as an indicator of gene regulation». General \& Comparative Endocrinology, 121: 250-260.

[62] DANGRE, A.J.; MANNING, S. eta BROUWER, M. 2010. «Effects of cadmium on hypoxia-induced expression of hemoglobin and erythropoietin in larval sheepshead minnow, Cyprinodon variegates». Aquatic Toxicology, 99: 168-175.

[63] HAGENAARS, A.; KNAPEN, D.; MEYER, I.J.; VAN DER VEN, K.; HOFF, P. eta DE COEN, W. 2008. «Toxicity evaluation of perfluorooctane sulfonate (PFOS) in the liver of common carp (Cyprinus carpio)». Aquatic Toxicology, 88: 155-163.

[64] MOENS, L.N.; SOETAERT, A.; VAN DER VEN, K.; DEL-FAVERO, J. eta DE COEN, W.M. 2007. «Use of suppression subtractive hybridization PCR for the development of cDNA arrays for the detection of endocrine disruption in carp (Cyprinus carpio)». Comparative Biochemistry \& Physiology, 2: 18-33.

[65] FUJIKI, K.; SHIN, D.; NAKAO, M. eta YANO, T. 2000. «Molecular cloning and expression analysis of carp (Cyprinus carpio) interleukin-1 $\beta$, high affinity immunoglobulin E Fc receptor $\gamma$ subunit and serum amyloid A». Fish \& Shellfish Immunology, 10: 229-242.

[66] REYNDERS, H.; VAN DER VEN, K.; MOENS, L.N.; VAN REMORTEL, P.; DE COENA, W.M. eta BLUST, R. 2006. «Patterns of gene expression in carp liver after exposure to a mixture of waterborne and dietary cadmium using a custom-made microarray». Aquatic Toxicology, 80: 180-193.

[67] NOGUEIRA, P.; PACHECO, M.; PEREIRA, M.L.; MENDO, S. eta ROTCHELL, J.M. 2010. «Anchoring novel molecular biomarker responses to traditional responses in fish exposed to environmental contamination». Environmental Pollution, 158: 1783-1790.

[68] BOUTET, I.; KY, C.L. eta BONHOMME, F. 2006. «A transcriptomic approach of salinity response in the euryhaline teleost, Dicentrarchus labrax.» Gene, 379: 40-50.

[69] WANG, L. eta WU, X. 2007. «Identification of differentially expressed genes in lipopolysaccharide-stimulated yellow grouper Epinephelus awoara spleen». Fish \& Shellfish Immunology, 23: 354-363. 
[70] CHEN, Y.Y.M.; KUO, C.E.; WANG, T.Y.; SHIE, P.S.; WANG, W.C.; HUANG, S.L.; TSAI, T.J.; CHEN, P.P.; CHEN, J.C. eta CHEN, T.Y. 2010. «Cloning of an orange-spotted grouper Epinephelus coioides heat shock protein $90 \mathrm{AB}$ (HSP90AB) and characterization of its expression in response to nodavirus». Fish \& Shellfish Immunology, 28(5-6), 895-904.

[71] MEYER, J.N.; VOLZ, D.C.; FREEDMAN, J.H. eta DI GIULIO, R.T. 2005. «Differential display of hepatic mRNA from killifish (Fundulus heteroclitus) inhabiting a Superfund estuary». Aquatic Toxicology, 73, 327-341.

[72] PETERSON, J. eta BAIN, L.J. 2004. «Differential gene expression in anthracene-exposed mummichogs (Fundulus heteroclitus)». Aquatic Toxicology, 66: 345-355.

[73] GONZALEZ, H.O.; ROLING, J.A.; BALDWIN, W.S. eta BAIN, L.J. 2006. «Physiological changes and differential gene expression in mummichogs (Fundulus heteroclitus) exposed to arsenic.» Aquat Toxicol. 77(1):43-52.

[74] ROLING, J.A.; BAIN, L.J. eta BALDWIN, W.S. 2004. «Differential gene expression in mummichogs (Fundulus heteroclitus) following treatment with pyrene: comparison to a creosote contaminated site.» Marine Environmental Research, 57: 377-395.

[75] LILLEENG, E.; FRØYSTAD, M.K.; VEKTERUD, K.; VALEN, E.C. eta KROGDAHL, A. 2007. «Comparison of intestinal gene expression in Atlantic cod (Gadus morhua) fed standard fish meal or soybean meal by means of suppression subtractive hybridization and real-time PCR». Aquaculture, 267: 269-283.

[76] RISE, M.L.; HALL, J.; RISE, M.; HORI, T.; GAMPERL, A.K.; KIMBALL, J.; HUBERT, S.; BOWMAN, S. eta JOHNSON, S.C. 2008. Functional genomic analysis of the response of Atlantic cod (Gadus morhua) spleen to the viral mimic polyriboinosinic polyribocytidylic acid (pIC). Developmental Comparative Immunology, 32(8), 916-931.

[77] FURNES, C. eta ROBERTSEN, B. 2010. «Molecular cloning and characterization of bloodthirsty from Atlantic cod (Gadus morhua).» Fish \& Shellfish Immunology, 29: 903-909.

[78] FENG, C.Y.; JOHNSON, S.C.; HORI, T.S.; RISE, M.; HALL, J.R.; GAMPERL, A.K.; HUBERT, S.; KIMBALL, J.; BOWMAN, S. eta RISE, M.L. 2009. «Identification and analysis of differentially expressed genes in immune tissues of Atlantic cod stimulated with formalin-killed, atypical Aeromonas salmonicida.» Physiological Genomics, 37: 149-163.

[79] BROWN, M.M.; WILLIAMS, T.D.; CHIPMAN, J.K.; KATSIADAKI, I.; SANDERS, M. eta CRAFT, J.A. 2008.«Construction of subtracted EST and normalised cDNA libraries from liver of chemical-exposed three-spined stickleback (Gasterosteus aculeatus) containing pollutant-responsive genes as a resource for transcriptome analysis». Marine Environmental Research. $6,127-130$.

[80] GEOGHEGAN, F.; KATSIADAKI, I.; WILLIAMS, T.D. eta CHIPMAN, J.K. 2008. «A cDNA microarray for the three-spined stickle back, Gasteros- 
teus aculeatus L. and analysis of the interactive effects of oestradiol and dibenzanthracene exposures». J. of Fish Biology, 72, 2133-2153.

[81] ALVES-COSTA, F.A. eta WASKO, A.P. 2010. «Identification of sexually dimorphic gene expression in brain tissue of the fish Leporinus macrocephalus through mRNA differential display and real time PCR analyses». Genetica, 138(3), 321-331.

[82] NOGUEIRA, P.; PACHECO, M.; PEREIRA M.L.; MENDO, S. eta ROTCHELL, J.M. 2010. «Anchoring novel molecular biomarker responses to traditional responses in fish exposed to environmental contamination». Environ Pollut. 158(5):1783-90.

[83] BOWMAN, C.J.; KROLL, K.J.; GROSS, T.G. eta DENSLOW, N.D. 2002. «Estradiol-induced gene expression in largemouth bass (Micropterus salmoides)». Molecular \& Cellular Endocrinology, 31, 67-77.

[84] DENSLOW, N.D.; KOCERHA, J.; SEPÚLVEDA, M.S.; GROSS, T. eta HOLM, S.E. 2004. «Gene expression fingerprints of largemouth bass (Micropterus salmoides) exposed to pulp and paper mill effluents». Mutation Research, 552: 19-34.

[85] BLUM, J.L.; KNOEBL, I.; LARKIN, P.; KROLL, K.J. eta DENSLOW, N.D. 2004. «Use of suppressive subtractive hybridization and cDNA arrays to discover patterns of altered gene expression in the liver of dihydrotestosterone and 11-ketotestosterone exposed adult male largemouth bass (Micropterus salmoides)». Marine Environmental Research, 58(2-5), 565-9.

[86] BAYNE, C.J.; GERWICK, L.; FUJIKI, K.; NAKAO, M. eta YANO, T. 2001. «Immune-relevant (including acute phase) genes identified in the livers of rainbow trout, Oncorhynchus mykiss, by means of suppression subtractive hybridization». Development \& Comparative Immunology, 25, 205-217.

[87] SANGRADOR-VEGAS, A.; MARTIN,S.A.M.; O'DEA, P.G. eta SMITH, T.J. 2000. «Cloning and characterization of the Rainbow trout (Oncorhynchus mykiss) type II interleukin-1 receptor cDNA». Eur. J. Biochem. 267, 7031-7037.

[88] FUJIKI, K.; SMITH, C.M.; LIU, L.; SUNDICK, R.S. eta DIXON, B. 2003. «Alternate forms of MHC class II-associated invariant chain are not produced by alternative splicing in rainbow trout (Oncorhynchus mykiss) but are encoded by separate genes». Developmental \& Comparative Immunology, 27: 377-391.

[89] ILIEV, D.B.; GOETZ, G.V.; MACKENZIE, S.; PLANAS, J.V. eta GOETZ, F.W. 2006. «Pathogen-associated gene expression profiles in rainbow trout macrophages». Comparative Biochemistry \& Physiology, 1, 416-422.

[90] RHODES, L.D.; WALLISA, S. eta DEMLOW, S.E. 2009. «Genes associated with an effective host response by Chinook salmon to Renibacterium salmoninarum». Developmental Comparative Immunology, 33: 176-186. 
[91] FIOL, D.F.; CHAN, S.Y. eta KÜLTZ, D. 2006. «Identification and pathway analysis of immediate hyperosmotic stress responsive molecular mechanisms in tilapia (Oreochromis mossambicus) gill». Comparative Biochemistry \& Physiology - Part D: Genomics \& Proteomics, 1: 344-356.

[92] COLLI-DULÁ, R.; ZÚÑIGA-AGUILAR, J.J.; ALBORES-MEDINA, A. eta ZAPATA-PEREZ, O. 2009. «Identification of genes expressed as a result of lindane exposure in Oreochromis niloticus using differential display». Ecotoxicology \& Environmental Safety, 72, 1406-1412.

[93] D'COTTA, H.; GUIGUEN, A.Y.; GOVOROUN, M. eta FOSTIER, J.D. 2001. «Search for genes involved in the temperature-induced gonadal sex differentiation in the tilapia, Oreochromis niloticus.» J. of Experimental Zoology, 290(6), 574-85.

[94] VOLZ, D.C.; BENCIC, D.C.; HINTON, D.E.; LAW, J.M. eta KULLMAN, S.W. 2005. «2,3,7,8-Tetrachlorodibenzo-pdioxin (TCDD) induces organspecific differential gene expression in Japanese medaka (Oryzias latipes)». Toxicological Sciences, 85(1): 572-584.

[95] KOH, S.C.; SHIN, S.W.; CHO, H.D.; CHON, T.S.; KIM, J.S. eta LEE, S.K. 2009. «Selection of molecular biomarkers relevant to abnormal behaviors of medaka fish (Oryzias latipes) caused by diazinon». J. of Environmental Toxicology, 24, 321-332.

[96] RICHARDS, R.C.; ACHENBACH, J.C.; SHORT, C.E.; KIMBALL, J.; REITH, M.E.; DRIEDZIC, W.R. eta EWART, K.V. 2008. «Seasonal expressed sequence tags of rainbow smelt (Osmerus mordax) revealed by subtractive hybridization and the identification of two genes up-regulated during winter». Gene, 424(1-2), 56-62.

[97] MATSUYAMA, T.; FUJIWARA, A.; TAKANO, T. eta NAKAYASU, C. 2011. «Suppression subtractive hybridization coupled with microarray analysis to examine differential expression of genes in Japanese flounder Paralichthys olivaceus leucocytes during Edwardsiella tarda and viral hemorrhagic septicemia virus infection». Fish \& Shellfish Immunology, 31(4), $524-32$.

[98] KNOEBL, I.; BLUM, J.L.; HEMMER, M.J. eta DENSLOW, N.D. 2006. «Temporal gene induction patterns in sheepshead minnow exposed to $17 \beta-$ estradiol». J. of Experimental Zoology. Part A: Comparative \& Experimental Biology, 305, 707-719.

[99] GUST, K.A.; WILBANKS, M.S.; GUAN, X.; PIROOZNIA, M.; HABIB, T.; YOO, L.; WINTZ, H.; VULPE, C.D. eta PERKINS, E.J. 2011. «Investigations of transcript expression in fathead minnow (Pimephales promelas) brain tissue reveal toxicological impacts of RDX exposure». Aquatic Toxicology, 101, 135-145.

[100] SHEADER, D.L.; GENSBERG, K.; LYONS, B.P. eta CHIPMAN, J.K. 2004. «Isolation of differentially expressed genes from contaminant exposed European flounder by suppressive, subtractive hybridization». Marine Environmental Research, 58, 553-557. 
[101] MARCHAND, J.; TANGUY, A.; CHARRIER, G.; QUINIOU, L.; PLEEGAUTHIER, E. eta LAROCHE, J. 2006.« Molecular Identification and expression of differentially regulated genes of the European flounder, Platichthys flesus, submitted to pesticide exposure». Marine Biotechnology, 8 , 275-294.

[102] SHEADER, D.L.; WILLIAMS, T.D.; LYONS, B.P. eta CHIPMAN, J.K. 2006. «Oxidative stress response of European flounder (Platichthys flesus) to cadmium determined by a custom cDNA microarray». Marine Environmental Research, 62: 33-44.

[103] WILLIAMS, T.D.; GENSBERG, K.; MINCHIN, S.D. eta CHIPMAN, J.K. 2003. «A DNA expression array to detect toxic stress response in European flounder (Platichthys flesus)». Aquat Toxicol. 65(2):141-57.

[104] LI, C.H.; CHEN, J.; SHI, Y.H. eta LU, X.J. 2011. «Use of suppressive subtractive hybridization to identify differentially expressed genes in ayu (Plecoglossus altivelis) associated with Listonella anguillarum infection». Fish \& Shellfish Immunology, 31(3): 500-6.

[105] BALDWIN, W.S.; ROLING, J.A.; PETERSON, S. eta CHAPMAN, L.M. 2005. «Effects of nonylphenol on hepatic testosterone metabolism and the expression of acute phase proteins in winter flounder (Pleuronectes americanus): Comparison to the effects of Saint John's Wort». Comparative Biochemistry \& Physiology - Part C: Toxicology \& Pharmacology, 140(1), 87-96.

[106] BROWN, M.M.; WILLIAMS, T.D.; CHIPMAN, J.K.; KATSIADAKI, I.; SANDERS, M. eta CRAFT, J.A. 2008.« Construction of subtracted EST and normalised cDNA libraries from liver of chemical-exposed threespined stickleback (Gasterosteus aculeatus) containing pollutant-responsive genes as a resource for transcriptome analysis». Marine Environmental Research, 66, 127-130.

[107] HUMBLE, J.L.; HANDS, E.; SAARISTO, M.; LINDSTRÖM, K.; LEHTONEN, K.K.; DIAZ DE CERIO, O.; CANCIO, I.; WILSON, G. eta CRAFT, J.A.. 2013. «Characterisation of genes transcriptionally upregulated in the liver of sand goby (Pomatoschistus minutus) by $17 \alpha$-ethinyloestradiol: identification of distinct vitellogenin and zona radiata protein transcripts» Chemosphere. 90(11), 2722-9.

[108] CHAPMAN, L.M.; ROLING, J.A.; BINGHAM, L.K.; HERALD, M.R. eta BALDWIN, W.S. 2004. «Construction of a subtractive library from hexavalent chromium treated winter flounder (Pseudopleuronectes americanus) reveals alterations in non-selenium glutathione peroxidases.» Aquat Toxicol. 67(2):181-94.

[109] STRAUB, P.F.; HIGHAM, M.L.; TANGUY, A.; LANDAU, B.J.; PHOEL, W.C.; HALES, L.S. eta THWING, T. 2004. «Suppression subtractive hybridization cDNA libraries to identify differentially expressed genes from contrasting fish habitats». Marine Biotechnology, 6, 386-399.

[110] HUANG, Y.; HUANG, X.; YAN, Y.; CAI, J.; OUYANG, Z.; CUI, H.; WANG, P. eta QIN, Q. 2011. «Transcriptome analysis of orange-spotted 
Deskodetutako arrainak: atzo, gaur eta bihar

grouper (Epinephelus coioides) spleen in response to Singapore grouper iridovirus». BMC Genomics, 12(1): 556.

[111] WEI, W.; WU, H.; XU, H.; XU, T.; ZHANG, X.; CHANG, K. eta ZHANG, Y. 2009. «Cloning and molecular characterization of two complement Bf/C2 genes in large yellow croaker (Pseudosciaena crocea)». Fish \& Shellfish Immunology, 27(2), 285-295.

[112] TSOI, S.C.M.; EWART, K.V.; PENNY, S.; MELVILLE, K.; LIEBSCHER, K.S.; BROWN, L.L. eta DOUGLAS, S.E. 2004. «Identification of immune-relevant genes from Atlantic salmon using suppression subtractive hybridization.» Marine Biotechnology, 6, 199-214.

[113] MARTIN, S.; BLANEY, S.C.; HOULIHAN, D.F. eta SECOMBES, C.J. 2006. «Transcriptome response following administration of a live bacterial vaccine in Atlantic salmon (Salmo salar).» Molecular Immunology, 43: 1900-1911.

[114] MARJARA, I.S.; THU, B.J. eta EVENSEN, Ø. 2010. «Differentially expressed genes following persistent infection with infectious pancreatic necrosis virus in vitro and in vivo.» Fish \& Shellfish Immunology, 28, 845-853.

[115] MORTENSEN, A.S. eta ARUKWE, A. 2007. «Targeted salmon gene array (SalArray): a toxicogenomic tool for gene expression profiling of interactions between estrogen and aryl hydrocarbon receptor signalling pathways». Chem Res Toxicol. 20(3), 474-88.

[116] TINE, M.; DE LORGERIL, J.; D'COTTA, H.; PEPEY, E.; BONHOMME, F.; BAROILLER, J.F. eta DURAND, J.D. 2008. «Transcriptional responses of the black-chinned tilapia Sarotherodon melanotheron to salinity extremes.» Marine Genomics, 1, 37-46.

[117] PRIETO-ÁLAMO, M.; ABRIL, N.; OSUNA-JIMÉNEZ, I. eta PUEYO, C. 2009. «Solea senegalensis genes responding to lipopolysaccharide and copper sulphate challenges: Large-scale identification by suppression subtractive hybridization and absolute quantification of transcriptional profiles by real-time RT-PCR ». Aquatic Toxicology, 91, 312-319.

[118] RIBAS, L.; PLANAS, J.V.; BARTON, B.; MONETTI, C.; BERNADINI, G.; SAROGLIA, M.; TORT, L. eta MACKENZI, S. 2004. «A differentially expressed enolase gene isolated from the gilthead sea bream (Sparus aurata) under high-density conditions is up-regulated in brain after in vivo lipopolysaccharide challenge». Aquaculture, 241, 195-206.

[119] DIOS, S.; POISA-BEIRO, L.; FIGUERAS, A. eta NOVOA, B. 2007. «Suppression subtraction hybridization (SSH) and macroarray techniques reveal differential gene expression profiles in brain of sea bream infected with nodavirus». Molecular Immunology, 44, 2195-2204.

[120] DAVEY, G.C.; CALDUCH-GINER, J.A.; HOUEIX, B.; TALBOT, A.; SITJÀ-BOBADILLA, A.; PRUNET, P.; PÉREZ-SÁNCHEZ, J. eta CAIRNS, M.T. 2011. «Molecular profiling of the gilthead sea bream (Sparus aurata L.) response to chronic exposure to the myxosporean parasite Enteromyxum leei». Molecular Immunology, 48(15-16), 2102-12. 
[121] LIARTE, S.; CHAVES-POZO, E.; ABELlÁN, E.; MESEGUER, J.; MULERO, V.; CANARIO, A.V.M. eta GARCÍA-AYALA, A. 2011. «Estrogen-responsive genes in macrophages of the bony fish gilthead seabream: A transcriptomic approach.» Developmental Comparative Immunology, 35: 840-849.

[122] ILIEV, D.B.; CASTELlANA, B.; MACKENZIE, S.; PLANAS, J.V. eta GOETZ, F.W. 2007. «Cloning and expression analysis of an IL-6 homolog in rainbow trout (Oncorhynchus mykiss).» Molecular Immunology, 44, 1803-1807.

[123] MOLlENHAUER, M.; CARTER, B.J.; PEDEN-ADAMS, M.M.; BOSART, D. eta FAI, P.A. 2009. «Gene expression changes in bottlenose dolphin, Tursiops truncatus, skin cells following exposure to methylmercury (MeHg) or perfluorooctane sulfonate (PFOS)». Aquatic Toxicology, 91, 10-18.

[124] GARCIA-REYERO, N.; GRIFFITT, J.; LIU, L.; KROLL, K.J.; FARMERIE, W.G.; BARBER, D.S. eta DENSLOW, N.D. 2008. «Construction of a robust microarray from a non-model species largemouth bass, Micropterus salmoides (Lacèpede), using pyrosequencing technology». J. of Fish Biology, 72, 2354-2376.

[125] KRISTIANSSON, E.; ASKER, N.; FÖRLIN, L. eta LARSSON, D.G. 2009. «Characterization of the Zoarces viviparus liver transcriptome using massively parallel pyrosequencing.» BMC Genomics, 10, 345.

[126] HALE, M.C.; MCCORMICK, C.R.; JACKSON, J.R. eta DEWOOD, J.A. 2009. «Next-generation pyrosequencing of gonad transcriptomes in the polyploid lake sturgeon (Acipenser fulvescens): the relative merits of normalization and rarefaction in gene discovery». BMC Genomics, 10: 203.

[127] OLEKSIAK, M.F.; KARCHNER, S.I.; JENNY, M.J.; FRANKS, D.G.; WELCH, D.B. eta HAHN, M.E. 2011. «Transcriptomic assessment of resistance to effects of an aryl hydrocarbon receptor (AHR) agonist in embryos of Atlantic killifish (Fundulus heteroclitus) from a marine Superfund site.» BMC Genomics. 24, 12:263.

[128] JOHANSEN, S.D.; KARLSEN, B.O.; FURMANEK, T.; ANDREASSEN, M.; JØRGENSEN, T.E.; BIZUAYEHU, T.T.; BREINES, R.; EMBLEM, A.; KETTUNEN, P.; LUUKKO, K.; EDVARDSEN, R.B.; NORDEIDE, J.T.; COUCHERON, D.H. eta MOUM, T. 2011. «RNA deep sequencing of the Atlantic cod transcriptome» Comparative Biochemistry \& Physiology Part D: Genomics \& Proteomics, 6(1), 18-22.

[129] LANES, C.F.; BIZUAYEHU, T.T.; DE OLIVEIRA FERNANDES, J.M.; KIRON, V. eta BABIAK, I.2013. «Transcriptome of Atlantic cod (Gadus morhua L.) early embryos from farmed and wild broodstocks.» Mar Biotechnol (NY). 15(6), 677-94.

[130] HUANG, Y.; HUANG, X.; YAN, Y.; CAI, J.; OUYANG, Z.; CUI, H.; WANG, P. eta QIN, Q. 2011. «Transcriptome analysis of orange-spotted grouper (Epinephelus coioides) spleen in response to Singapore grouper iridovirus». BMC Genomics. 12, 556. 
[131] GAGNAIRE, P.A.; NORMANDEAU, E.; CÔTÉ, C.; HANSEN, M.M. eta BERNATCHEZ L. 2012. «The genetic consequences of spatially varying selection in the panmictic American eel (Anguilla rostrata). » Genetics. 190(2), 725-36.

[132] FRASER, B.A.; WEADICK, C.J.; JANOWITZ, I.; RODD, H. eta HUGHES, K.A. 2011. «Sequencing and characterization of the guppy (Poecilia reticulata) transcriptome.» BMC Genomics ,12(1), 202.

[133] RHEE, J.S.; KIM, B.M.; KIM, R.O.; CHOI, B.S.; CHOI, I.Y.; LEE, Y.M. eta LEE, J.S. 2011. «Analysis of expressed sequence tags from the liver and ovary of the euryhaline hermaphroditic fish, Kryptolebias marmoratus.» Comparative Biochemistry \& Physiology - Part D: Genomics \& Proteomics. 6(3), 244-255.

[134] WHANG, I.; LEE, Y.; LEE, S.; OH, MJ.; JUNG, S.J.; CHOI, C.Y.; LEE, W.S.; KIM, H.S.; KIM, S.J. eta LEE, J. 2011. «Characterization and expression analysis of a goose-type lysozyme from the rock bream Oplegnathus fasciatus, and antimicrobial activity of its recombinant protein.» Fish Shellfish Immunol. 30(2), 532-42.

[135] TAKECHI, M.; TAKEUCHI, M.; OTA, K.G. et al. 2011. «Overview of the transcriptome profiles identified in hagfish, shark, and bichir: current issues arising from some nonmodel vertebrate taxa.» J. Exp. Zool. B Mol. Dev. Evol. 316(7), 526-46.

[136] JEUKENS, J.; RENAUT, S.; ST-CYR, J.; NOLTE, A.W. eta BERNATCHEZ, L. 2010. «The transcriptomics of sympatric dwarf and normal lake whitefish (Coregonus clupeaformis spp, Salmonidae) divergence as revealed by next-generation sequencing.» Molecular Ecology, 19(24), 53895403.

[137] RENAUT S.; NOLTE, A.W. eta BERNATCHEZ, L.2010.«Mining transcriptome sequences towards identifying adaptive single nucleotide polymorphisms in lake whitefish species pairs (Coregonus spp. Salmonidae)». Mol Ecol. 19:115-31.

[138] PIERRON, F.; NORMANDEAU, E.; DEFO, M.A.; CAMPBELL, P.G.; BERNATCHEZ, L. eta COUTURE, P. 2011. «Effects of chronic metal exposure on wild fish populations revealed by high-throughput cDNA sequencing». Ecotoxicology, 20(6), 1388-99.

[139] YÚFERA, M.; HALM, S.; BELTRAN, S.; FUSTÉ, B.; PLANAS, J.V. eta MARTÍNEZ-RODRÍGUEZ, G. 2012. «Transcriptomic characterization of the larval stage in gilthead seabream (Sparus aurata) by 454 pyrosequencing.» Marine Biotechnology. 14, 423-435.

[140] GARCIA DE LA SERRANA CASTILLO, D.; ESTEVEZ, A.; ANDREE, K. eta JOHNSTON, I. A. 2012. «Fast skeletal muscle transcriptome of the Gilthead sea bream (Sparus aurata) determined by next generation sequencing» BMC Genomics, 13, 181.

[141] CALDUCH-GINER, J.A.; BERMEJO-NOGALES, A.; BENEDITO-PALOS, L.; ESTENSORO, I.; BALLESTER-LOZANO, G.; SITJÀ-BOBA- 
DILLA, A. eta PÉREZ-SÁNCHEZ, J. 2013. «Deep sequencing for de novo construction of a marine fish (Sparus aurata) transcriptome database with a large coverage of protein-coding transcripts.» BMC Genomics, 14, 178.

[142] PEREIRO, P.; BALSEIRO, P.; ROMERO, A.; DIOS, S.; FORN-CUNI, G.; FUSTE, B.; PLANAS, J.V.; BELTRAN, S.; NOVOA, B. eta FIGUERAS, A. 2012. «High-throughput sequence analysis of turbot (Scophthalmus maximus) transcriptome using 454-pyrosequencing for the discovery of antiviral immune genes.» PLoS One, 7, e35369.

[143] RIBAS, L.; PARDO, B.G.; FERNÁNDEZ, C.; ÁLVAREZ-DIÓS, J.A.; GÓMEZ-TATO, A.; QUIROGA, M.I.; PLANAS, J.V.; SITJÀ-BOBADILLA, A.; MARTÍNEZ, P. eta PIFERRER, F. 2013. «A combined strategy involving Sanger and 454 pyrosequencing increases genomic resources to aid in the management of reproduction, disease control and genetic selection in the turbot (Scophthalmus maximus).» BMC Genomics, 14, 180.

[144] SARROPOULOU, E.; GALINDO-VILLEGAS, J.; GARCÍA-ALCÁZAR, A.; KASAPIDIS, P. eta MULERO V. 2012. «Characterization of european sea bass transcripts by RNA SEQ after oral vaccine against V. anguillarum.» Marine Biotechnology. 14, 634-642.

[145] GAO, Z.; LUO, W.; LIU, H.; ZENG, C.; LIU, X. et al. 2012. «Transcriptome Analysis and SSR/SNP Markers Information of the Blunt Snout Bream (Megalobrama amblycephala).» PLoS ONE 7(8): e42637.

[146] COPPE, A.; PUJOLAR, J.M.; MAES, G.E.; LARSEN, P.F.; HANSEN, M.M.; BERNATCHEZ, L.; ZANE, L. eta BORTOLUZZI, S. 2010. «Sequencing, de novo annotation and analysis of the first Anguilla anguilla transcriptome: EeelBase opens new perspectives for the study of the critically endangered european eel.» BMC Genomics. 11, 635.

[147] PUJOLAR, J.M.; MARINO, I.A.; MILAN, M.; COPPE, A. et al. 2012. «Surviving in a toxic world: transcriptomics and gene expression profiling in response to environmental pollution in the critically endangered European eel.» BMC Genomics. 13, 507.

[148] SHIN SC, KIM SJ, LEE JK, AHN DH, KIM MG, ET AL. 2012 «Transcriptomics and Comparative Analysis of Three Antarctic Notothenioid Fishes». PLoS ONE 7(8):e43762.

[149] GROSS, J.B, FURTERER, A.; CARLSON B.M. eta STAHL B.A. 2013 «An Integrated Transcriptome-Wide Analysis of Cave and Surface Dwelling Astyanax mexicanus.» PLoS ONE 8(2): e55659. doi:10.1371/journal. pone.0055659.

[150] HAASE, D.; ROTH, O.; KALBE, M.; SCHMIEDESKAMP, G.; SCHARSACK, J.P.; ROSENSTIEL, P. et al. 2013. «Absence of major histocompatibility complex class II mediated immunity in pipefish, Syngnathus typhle: evidence from deep transcriptome sequencing.» Biol. Lett. 9, 20130044

[151] GOMES, A.S.; ALVES, R.N.; STUEBER, K.; THORNE, M.A.S.; SMÁRADÓTTIR, H.; REINHARD, R.; CLARK, M.S.; RØNNESTAD, I. 
Deskodetutako arrainak: atzo, gaur eta bihar

eta POWER, D.M. 2014. " Transcriptome of the Atlantic halibut (Hippoglossus hippoglossus).» Marine Genomics. 3, pp. 10.1016/j.margen. 2014.07.005 (In Press).

[152] FERRARESSO, S.; BONALDO, A.; PARMA, L.; CINOTTI, S.; MASSI, P.; BARGELLONI, L. eta GATTA, P.P. 2013. «Exploring the larval transcriptome of the common sole (Solea solea L.).» BMC Genomics. 14, 315.

[153] OLSVIK, P.A.; BERG, V. eta LYCHE, J.L. 2013. «Transcriptional profiling in burbot (Lota lota) from Lake Mjøsa--a Norwegian Lake contaminated by several organic pollutants». Ecotoxicology and environmental safety. 92:94-103.

[154] TSE, W, SUN, J.; ZHANG, H.; LAW, A.Y.S.; YEUNG, B.H.Y.; CHOWA, S.C.; QIUA J.W. eta WONG, C.K.C. 2013. «Transcriptomic and iTRAQ proteomic approaches reveal novel short-term hyperosmotic stress responsive proteins in the gill of the Japanese eel (Anguilla japonica).» Journal of Proteomics. 89, 81-94.

[155] MONTES, I.; CONKLIN, D.; ALBAINA, A.; CREER, S.; CARVALHO, G.R.; SANTOS, M. eta ESTONBA, A. 2013. «SNP Discovery in European Anchovy (Engraulis encrasicolus, L) by High-Throughput Transcriptome and Genome Sequencing». PLoS ONE 8(8): e70051. DOI: 10.1371/ journal.pone.0070051.

[156] MUTZ, K.O.; HEILKENBRINKER, A.; LÖNNE, M.; WALTER, J.G. eta STAHL, F. 2013. «Transcriptome analysis using next-generation sequencing.» Current opinion in Biotechnology. 24(1), 22-30.

[157] PRADERVAND, S.; WEBER, J.; LEMOINE, F.; CONSALES, F.; PAILLUSSON, A.; DUPASQUIER, M.; THOMAS, J.; RICHTER, H.; KAESSMANN, H.; BEAUDOING, E.; HAGENBÜCHLE, O. eta HARSHMAN, K. 2010. «Concordance among digital gene expression, microarrays, and qPCR when measuring differential expression of microRNAs.» Biotechniques. 48(3):219-22.

[158] COSTA, V.; ANGELINI, C.; DE FEIS, I. eta CICCODICOLA, A. 2010. «Uncovering the Complexity of Transcriptomes with RNA-Seq. » Journal of Biomedicine and Biotechnology. 2010: 19.

[159] WILLENBROCK,H.; SALOMON,J.; SØKILDE, R.; BARKEN, K.B.; HANSEN, T.N.; NIELSEN, F.C.; MØLLER, S. eta LITMAN, T. 2009. «Quantitative miRNA expression analysis: Comparing microarrays with next-generation sequencing». RNA. 15(11): 2028-2034.

[160] QIAN, X.; BA, Y.; ZHUANG, Q. eta ZHONG, G. 2013. «RNA-Seq Technology and Its Application in Fish Transcriptomics». OMICS A Journal of Integrative Biology. 18, 1-13.

[161] HUANG, Y.; DONG. S.; FANG, C.; WU, X. eta YE, T. 2012. « Deep sequencing-based transcriptome profiling analysis of Oryzias melastigma exposed to PFOS ». Aquat Toxicol. 15, 54-8.

[162] SUN, S.; GE, X.; XUAN, F.; ZHU, J. eta YU, N. 2014. «Nitrite-induced hepatotoxicity in Bluntsnout bream (Megalobrama amblycephala): the 
mechanistic insight from transcriptome to physiology analysis». Environ Toxicol Pharmacol. 37(1), 55-65.

[163] UREN WEBSTER, T.M.; BURY, N.; VAN AERLE, R. eta SANTOS, E.M. 2013. «Global transcriptome profiling reveals molecular mechanisms of metal tolerance in a chronically exposed wild population of brown trout». Environ Sci Technol. 47(15), 8869-77.

[164] SULLIVAN, C. eta KIM, H. 2008. «Zebrafish as a model for infectious disease and immune function». Fish \& Shellfish Immunology, 25, 341-350. 